www.nhtsa.gov

\title{
Statistical Analysis of
}

\section{Alcohol-Related Driving Trends, 1982-2005}


The United States Government does not endorse products or manufacturers. Trade or manufacturers' names appear only because they are considered essential to the object of this report. 
Technical Report Documentation Page

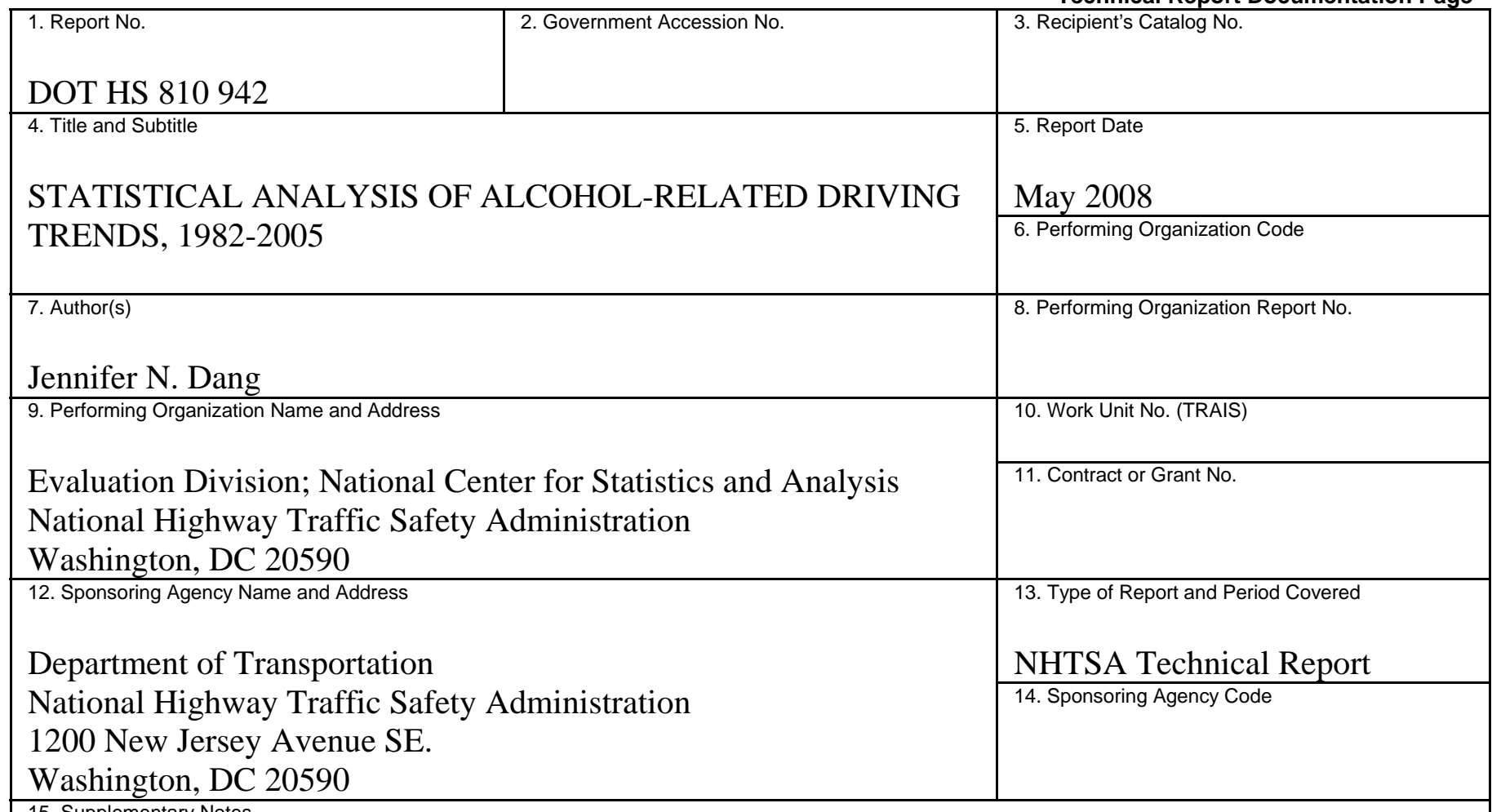

15. Supplementary Notes

Overall, the percent of drivers involved in fatal crashes who had consumed alcohol and had blood alcohol concentration (BAC) of .08 or above prior to the crash steadily decreased from 1982 to 1997 and then leveled off (more or less). In an attempt to explain the 1982-1997 reduction and the 1997-2005 level trend, this report presents a statistical analysis of factors that influenced the historical alcohol-related driving trends from 1982 to 2005.

The study is based on disaggregate logistic regression of imputed Fatality Analysis Reporting System (FARS) cases from all 50 States and the District of Columbia - to predict the probability of an alcohol-related involvement given a set of independent variables. The independent variables include alcohol-related legislation (i.e., .10 BAC, .08 BAC, Administrative License Revocation, minimum-legal-drinking-age laws), demographic factors (i.e., driver's age and gender), per capita alcohol consumption, and external factors (i.e., day of the week, time of day, roadway function class, and posted speed limit).

The independent variables explain both the decrease in alcohol-related fatal crashes (where drivers involved in fatal crashes had BAC of .08 or above) from 1982 to 1997 and its leveling off after 1997. Large portions of the reduction are explained by the effect of alcohol-laws and by the demographic trends - the aging of the population and the increased proportion of female drivers. The leveling off after 1997 does not imply that the laws are becoming less effective. On the contrary, they effectively maintain the proportion of drivers in fatal crashes who had BAC of .08 or above at the time of the crash - at the lowest level since 1982.

\begin{tabular}{|l|l|l|l|}
\hline $\begin{array}{l}\text { 17. Key Words } \\
\text { NHTSA; FARS; alcohol-related driving trends; } \\
\text { alcohol-related fatal crashes; statistical analysis; } \\
\text { evaluation; impaired driving; fatality reduction }\end{array}$ & $\begin{array}{l}\text { 18. Distribution Statement } \\
\text { Document is available to the public at the Docket } \\
\text { Management System of the U.S. Department of } \\
\text { Transportation, http://dms.dot.gov, }\end{array}$ \\
\begin{tabular}{l|l|l|} 
19. Security Classif. (Of this report) \\
Unclassified
\end{tabular} & $\begin{array}{l}\text { 20. Security Classif. (Of this page) } \\
\text { Unclassified }\end{array}$ & 69 & 22. Price \\
\hline
\end{tabular}

Form DOT F 1700.7 (8-72) $\quad$ Reproduction of completed page authorized 



\section{TABLE OF CONTENTS}

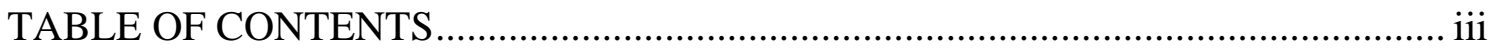

LIST OF ABBREVIATIONS.................................................................................. iv

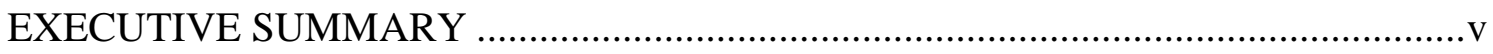

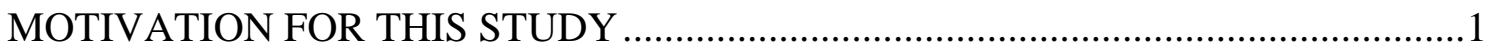

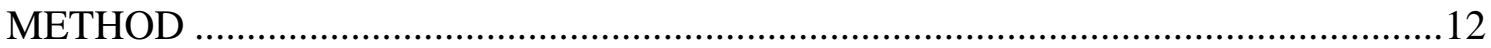

- MULTIPLE IMPUTATION METHOD

- DEPENDENT VARIABLE

- INDEPENDENT VARIABLES

$>$ DEMOGRAPHIC AND EXTERNAL VARIABLES

$>$ ADJUSTED PER CAPITA ALCOHOL CONSUMPTION

$>$ PROGRAMMATIC INDEPENDENT VARIABLES: ALCOHOL-RELATED LEGISLATION

$>$ OTHER POTENTIAL INDEPENDENT VARIABLES

- ANALYZING THE MULTIPLE-IMPUTED DATASETS IN FARS

- LOGISTIC REGRESSION

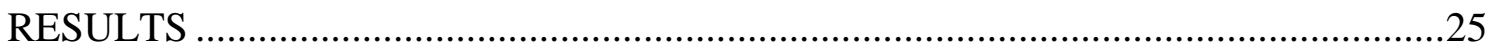

ANALYSIS OF ALCOHOL-RELATED DRIVING TRENDS INVOLVING ...............37 DRIVERS WITH BAC OF .01 OR ABOVE

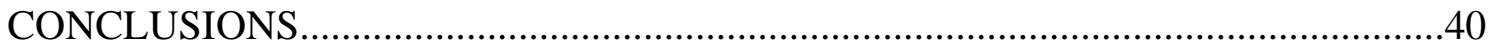

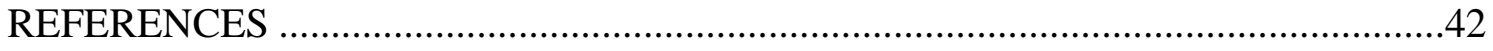

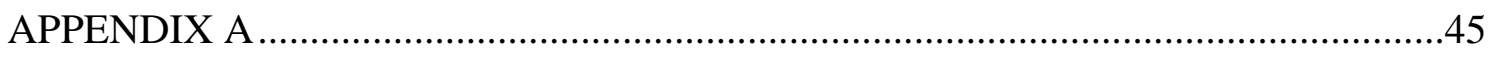

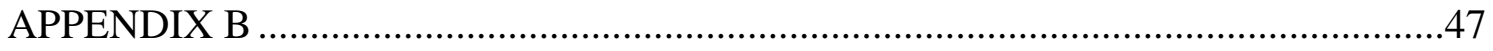

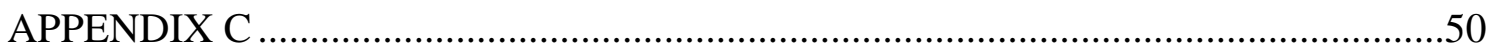

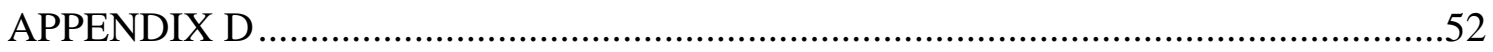

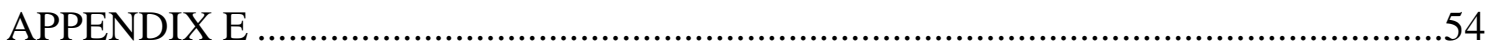




\section{LIST OF ABBREVIATIONS}

ALR Administrative License Revocation

BAC Blood alcohol concentration

DUI Driving under the influence

FARS Fatality Analysis Reporting System

MADD Mothers Against Drunk Driving

MLDA-21 Minimum Legal Drinking Age 21

NHTSA National Highway Traffic Safety Administration

SADD Students Against Destructive Decisions

SAS Statistical analysis software produced by SAS Institute, Inc. 


\section{EXECUTIVE SUMMARY}

The number of fatal crashes that involved drivers who had been drinking at the time of the crash has decreased during the past two decades. The proportion of crash fatalities that are alcohol-related - that occurred in crashes where at least one of the drivers and/or nonoccupants involved had a blood alcohol concentration (BAC) of .08 or above decreased at a steady rate from 53 percent in 1982 to 34 percent in 1997. It leveled off for two years and then increased by 1 percent in 2000 and remained at that level for two more years before it decreased to 33 percent in 2005. The proportion of drivers involved in fatal crashes who had BAC of .08 or above decreased from 35 percent in 1982 to 20 percent in 1997 and leveled off thereafter, as shown in Figure 1.

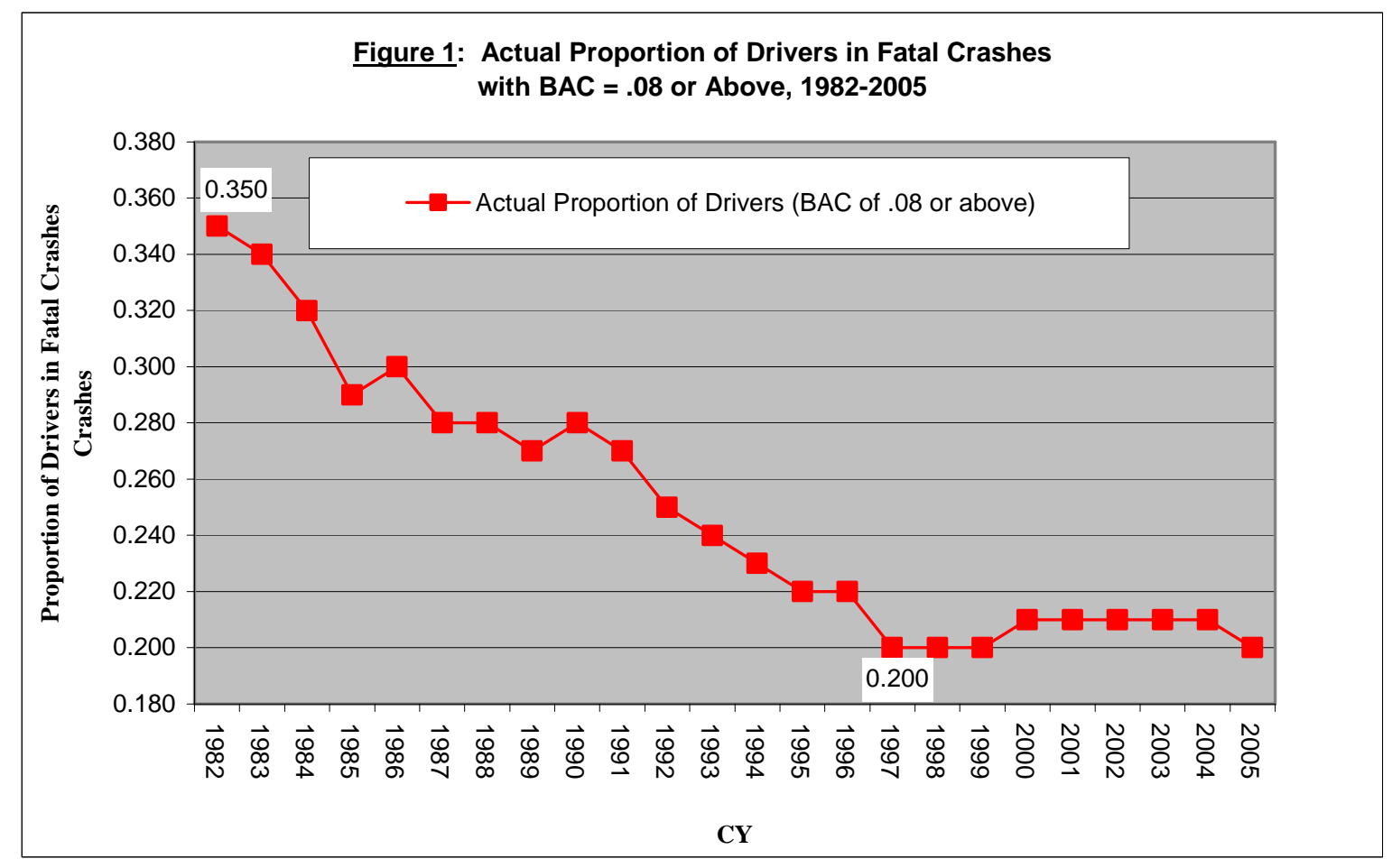

Tireless efforts were made in the last 20 years through legislative enactments and programs that were funded by States, communities, and private organizations to deter impaired driving. These alcohol programs and laws served as a general deterrent to all those who drink and drive by sending a message that the States were getting tougher on impaired driving and hence, these efforts made people think twice about getting behind the wheel after they had been drinking. In fact, the directional trend of the proportion of alcohol-related crash fatalities involving a driver and/or nonoccupant with BAC of .01 or above is similar to the crash fatality trend where the BAC of a crash-involved driver 
and/or nonoccupant is .08 or above. Moreover, the directional trend of the proportion of drivers in fatal crashes with BAC of .01 or higher is similar to the trend in Figure 1.

In 1998, the National Highway Traffic Safety Administration (NHTSA) contracted with a group of researchers (Voas and Tippetts) to study the "Relationship of Alcohol Safety Laws to Drinking Drivers in Fatal Crashes." Information on drivers in fatal crashes with positive BAC values for all 50 States and the District of Columbia from 1982 to 1997 was extracted from the Fatality Analysis Reporting System (FARS), and missing BAC data were imputed using Klein's method. 'That analysis attributed a substantial benefit to laws that deter impaired driving. However, the study period was limited to the years where alcohol-related fatal crashes were steadily decreasing (1982-1997) and before they leveled off. Post-1997 FARS data are now available. The leveling off of the alcoholrelated driving trend raised questions as to whether these alcohol programs are still as effective in deterring impaired driving as they were before. NHTSA has embarked on this update and modification of Voas and Tippetts's analysis.

This study uses logistic regression analysis to (1) provide clarification to the change in the historical alcohol-related driving trends - why they steadily decreased from 1982 to 1997 and why they leveled off after that period and (2) assess the effects of alcohol programs that directly and indirectly changed public attitudes and behavior toward drinking and driving during the last 20 years. In the first analysis, this study calibrates the probability that a driver involved in a fatal crash had a BAC of .08 or above. Since the two trends (specifically the proportion of drivers in fatal crashes with BAC of .08 or above and those with BAC of .01 or higher) are very similar, this study also predicts (in the second analysis) the likelihood that a driver involved in a fatal crash had a BAC of .01 or above. Logistic regression explores each driver as an individual, in order to calibrate the effects of legislation to deter alcohol-related driving while controlling for demographic factors (i.e., driver's age, gender), external factors (i.e., whether or not the crash occurred at night, on a weekday, on a rural roadway, and on a roadway with posted speed limit of 55 or greater) and per capita alcohol consumption. By contrast, the study by Voas and Tippetts aggregated the data by State and year, making it more difficult to isolate the effect of demographic and external factors that vary from crash to crash. This study is based on 1982-2005 FARS data for the 50 States and the District of Columbia** that include the estimates of alcohol involvement generated using Multiple Imputation

\footnotetext{
- Klein's method was the method being used in FARS at the time of Voas' and Tippetts' study to estimate BAC distributions for drivers with unknown BAC test results. It would calculate the probability that drivers in fatal crashes - where police reported alcohol information is unknown - had a BAC in grams per deciliter (g/dL) of .00, .01-.09, or .10+. For additional information, please refer to Klein, T. A Method for Estimating Posterior BAC Distributions for Persons Involved in Fatal Traffic Accidents. NHTSA Technical Report No. DOT HS 807 094, Washington, 1986.

** These 51 jurisdictions are all called "States" in the discussion that follows.
} 
when the BAC of drivers involved in fatal crashes is not explicitly reported, a technique that has superseded Klein's imputation method.

For both groups of drivers involved in fatal crashes (i.e., BAC of .08 or above and BAC of .01 or above), this study found that the 1982-1997 reductions in alcohol-related driving and the nearly level trends in 1997-2005 can be explained by the following:

- The benefits of five major types of State legislation to deter alcohol-related driving. All or most of these laws were in effect in the majority of States by 1997.

1) .10 BAC laws make it illegal to operate a motor vehicle at or above .10 $\mathrm{g} / \mathrm{dL}$. Most of the States passed this law during the 1980s. All 50 had passed .10 laws by 1997.

2) .08 BAC laws make it illegal to operate a motor vehicle at or above .08 g/dL. By 1997, 16 out of 51 States had enacted this law, and by 2005 every State had.

3) Administrative License Revocation (ALR) laws revoke or suspend the driver's license of an individual who refuses to submit to a BAC test or fails a test. By 1997, 40 out of 51 States had passed this law.

4) Minimum Legal Drinking Age 21 (MLDA-21) laws make it illegal for an individual under the age of 21 to drink. This law went into effect in every State during the 1980s.

5) Zero Tolerance laws make it illegal for an individual under the age of 21 to operate a vehicle with a BAC level of .02 or more. By 1997, 47 out of 51 States had passed this law.

- The decreasing proportion of population age 18-34 from 1982 to 1999, leveling off thereafter.

- The increasing proportion of licensed female drivers from 1982 to 1997, leveling off thereafter. Female drivers are generally much less likely to drink and drive than males.

- A small reduction in per capita alcohol consumption.

Logistic regression models make it possible to tease out the relative contributions of legislation, demographics, and per-capital alcohol consumption to the reduction in the proportion of drivers in fatal crashes who had BAC of .08 or above (first analysis) and

\footnotetext{
${ }^{* * *}$ Multiple imputation method is the method currently used in FARS to handle missing BAC data. It imputes ten specific values of BAC across the full range of possible values for each missing value rather than estimating probabilities.

* Currently, all 50 States and the District of Columbia have passed Zero Tolerance laws.
} 
those who BAC of .01 or above (second analysis), and to track the contributions over time. Figure 2 shows trend lines of predicted probability of an alcohol-related involvement of drivers in fatal crashes with BAC of .08 or above by models using none, some or all of the factors considered in the logistic regressions.

The horizontal line near the top of Figure 2 depicts the [unchanged] expected proportion of alcohol-related fatal crash involvements from 1982 to 2005 if (1) no new alcohol laws had gone into effect after December 31, 1981, (2) the public attitudes about alcohol had not changed, and (3) the driving population had not aged or otherwise changed. Hence, the expected proportion of drivers in fatal crashes with BAC of .08 or higher remains at 0.349 from 1982 through 2005.

The lowest curve in Figure 2 (short dashes of uniform length) shows the trend line predicted by the model controlling for all factors including the laws. The expected proportion of drivers with a BAC of .08 or above decreases from 0.336 in 1982 to 0.214 in 1998 and somewhat levels off afterward (actually it slightly decreases to 0.207 in 2005). This predicted trend closely follows the actual statistics shown in Figure 1.

The uppermost curve in Figure 2 (alternating long and short dashes) is the trend predicted by a model that includes the demographic factors, but not the variables on State laws and per capita alcohol consumption. In other words, it predicts what might have happened if the driving population had decreasing proportions of young and/or male drivers - as happened in reality - but State laws and per capita alcohol consumption had remained exactly the same as they were on December 31,1981 . This curve decreases from 0.349 in 1982 to 0.274 in 1998 and slightly increases to 0.278 in 2005. The curve shows how favorable demographic trends in 1982-1997 would, by themselves, have accounted for a substantial proportion of the overall reduction - even in the absence of programs to reduce alcohol-related driving. But because those demographic trends somewhat leveled off circa 1998 and one may even argue that there is a slight reversal in the trend toward an aging driver population, so did the non-uniform dashed curve. The light dotted region (upper portion of the graph) between the horizontal line and the non-uniform dashed curve denotes the year-by-year contribution of demographic factors to the overall reduction in the proportion of drivers in fatal crashes with BAC of .08 or greater.

The middle curve in Figure 2 (long dashes) is the trend predicted by a model that includes demographic factors and per capita alcohol consumption, but not State laws. It predicts what might have happened if demography and per capita alcohol consumption had changed as really happened - but State laws had remained exactly the same as they were on December 31, 1981. This curve decreases from 0.349 in 1982 to 0.269 in 1998 and levels off thereafter. Per capita consumption decreased from 1982 to1997, but the true reduction was relatively small after taking into account that the population was aging at the same time. The dark region (middle portion of the graph) between this curve and the one above it denotes the small contribution of reduced alcohol consumption to the overall decline in the proportion of drivers with BAC of .08 or above in fatal crashes. 
Finally, the light diamond shaped region (bottom portion of the graph) between the two lowest curves in Figure 2 measures the year-by-year contribution of State alcohol laws to the overall reduction in the proportion of drivers in fatal crashes with BAC of .08 or higher. The laws account for a substantial proportion of the overall effect, and their contribution grows steadily from 1982 to 1997. By 1997, most of these laws (except .08 BAC) had been enacted in most of the States. Three-fourths of the States did not pass .08 BAC laws until after 1997. The benefits of the laws continue to be substantial each year after 1997, but they do not grow as quickly because fewer new laws were enacted. The slight additional improvements in the overall trend in 1998-2005 may be attributed to a portion of the benefits of the $.08 \mathrm{BAC}$ laws.

As for the expected probability of an alcohol-related fatal crash involvements of drivers who had BAC of .01 or above at the time of the crash, the second logistic regression analysis predicted similar contributions of legislation, demographics, and per-capita alcohol consumption to the reduction in alcohol-related driving trend involving drivers with BAC of .01 or higher (Figure 2A).

The regression analyses also showed that each individual law was associated with a statistically significant reduction in alcohol-related driving for both groups of drivers (BAC of .08 or above and BAC of .01 or above): MLDA-21 and Zero Tolerance laws reduced alcohol involvement by individuals less than 21 years of age, while .10 BAC, .08 BAC, and ALR laws reduced alcohol involvement at all ages. Whereas the method of this report is not ideal for estimating the effects of individual laws, the findings are generally consistent with published time-series analyses of the effects of specific laws in individual States as well as with the findings of Voas and Tippetts. 


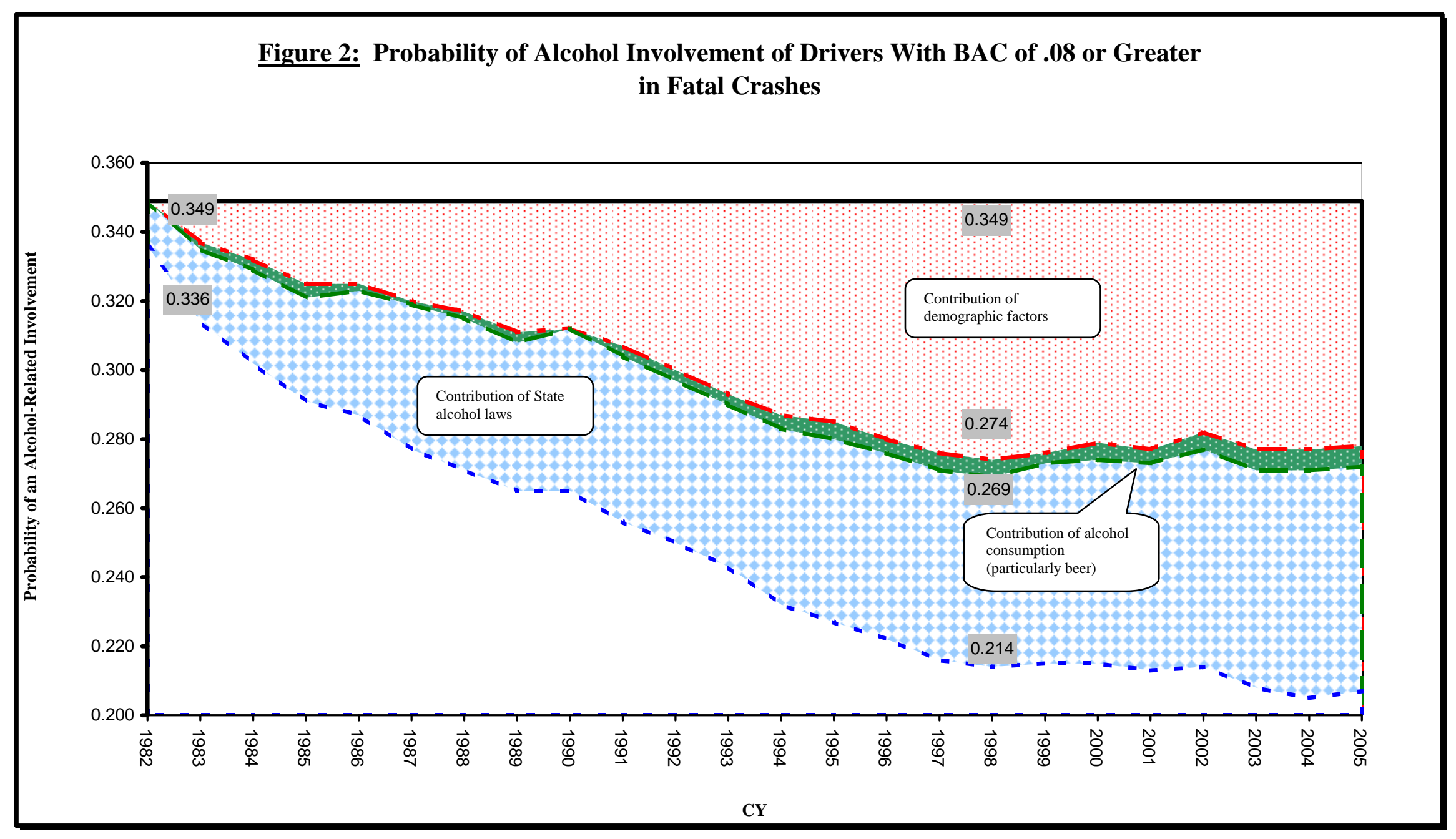




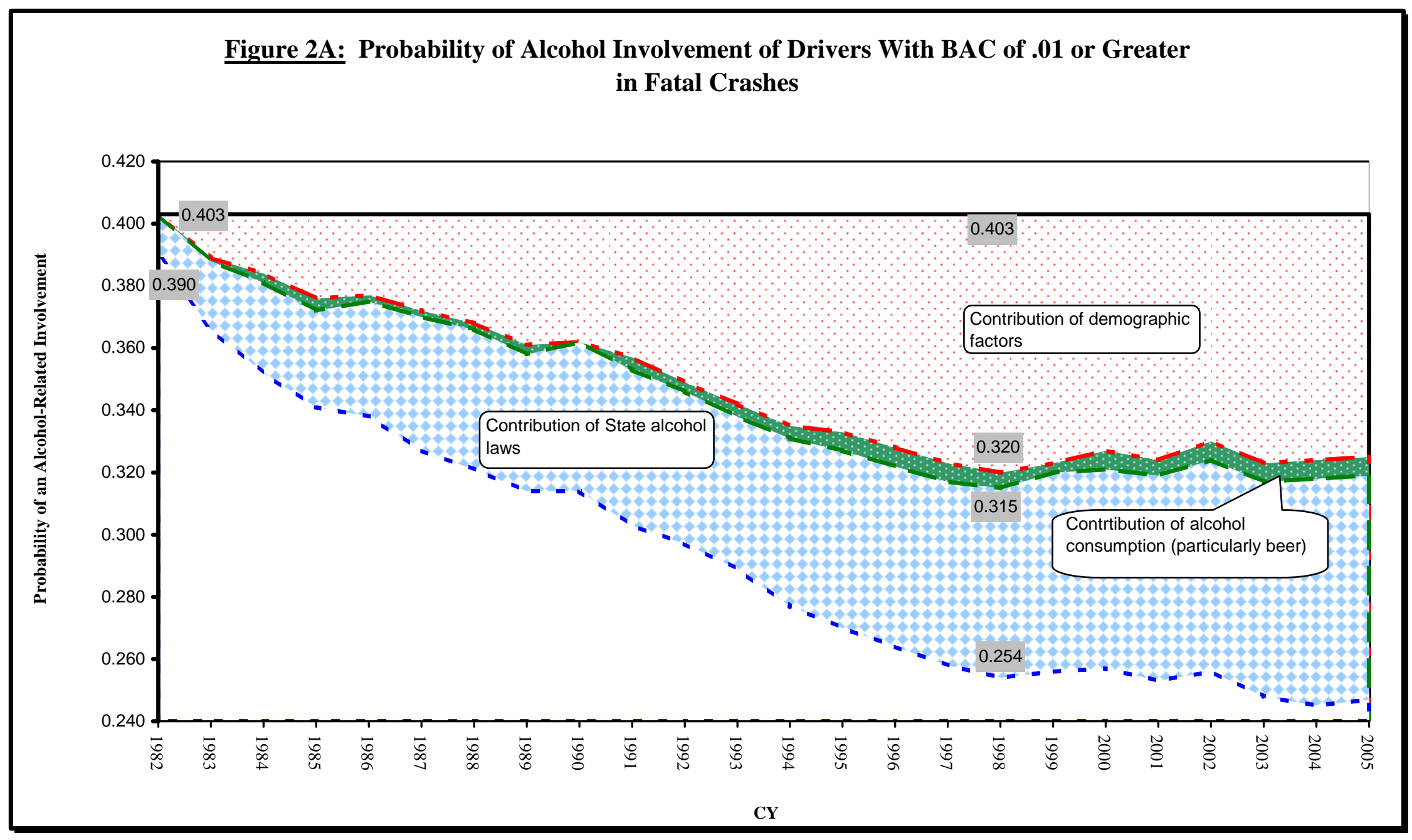


We explored other factors that might have contributed to the alcohol-related driving trends from 1982 to 2005: level of enforcement (e.g., number of DUI arrests, presence of sobriety checkpoints), alcohol excise tax rates, economic activity, seat belt laws, and the level of effort contributed by activist groups (e.g., MADD, SADD). We did not subsequently include them in the analysis because (1) index variables based on the number of DUI arrests (e.g., per capita, per gallon of alcohol consumed) did not have a significant correlation to the dependent variable (the ratio of drivers in fatal crashes with $\mathrm{BAC}>=.08$ to those with $\mathrm{BAC}=.00),(2)$ mere presence/absence of sobriety checkpoints did not have a significant correlation with the dependent variable (we did not have nationwide data to quantify the level of activity at the checkpoints), (3) both the historical Federal and State alcohol tax changes were quite small relative to the retail price of alcoholic beverages, (4) the country's economic activity - particularly the slowdowns of the economy in the early 1980s and early-mid 1990s - did not show any noteworthy association with the dependent variable, (5) because the relationship between seat belt laws and drivers in alcohol-related fatal crashes is complex and information on belt use by year and by State was not available, and (6) information on the number of MADD and SADD chapters by year and by State, needed for quantifying the level of effort by these activist groups was not readily available.

Although enforcement and activism (MADD, SADD) could not be directly included as variables in the model, it could be argued that their effect is implicitly present. Parts of the fatality reductions that the model attributes to the various laws is a consequence of the enforcement and publicity activities that have made the laws effective.

In conclusion, this study supports earlier findings that alcohol laws such as BAC, ALR, Zero Tolerance, and MLDA-21 significantly reduced (from 1982 to 1997) the proportion of drivers involved in fatal crashes who had BAC of .08 or higher as well as those who had BAC of .01 or higher. Demographics and alcohol laws each explain a considerable portion of the decrease in drunk driving from 1982 to 1997 and its leveling off in 19972005. The leveling off after 1997 does not in any way suggest that the laws are becoming less effective. On the contrary, they continue to successfully hold (1) the proportion of drivers with a BAC of .08 or above and (2) the proportion of drivers with BAC of .01 or above, close to the historically low 1997 rates. But there has been little additional improvement because the laws were already in effect in most of the States by 1997, and the demographic changes that reduced impaired driving had also leveled off. 


\section{Motivation for This Study}

The proportion of crash fatalities that are alcohol-related - that occurred in crashes where at least one driver and/or nonoccupant involved had a blood alcohol concentration (BAC) of .08 or higher - decreased at a steady rate from 53 percent in 1982 to 34 percent in 1997. It remained at 34 percent for two more years before it slightly increased (by 1\%) for three years and then decreased to an all time low of 33 percent in $2005 .{ }^{1}$ Similar to the proportion of crash fatalities that are alcohol-related, the proportion of drivers in fatal crashes - who had been drinking and had BAC of .08 or higher - decreased from 35 percent in 1982 to 20 percent in 1997. It remained at the lowest level for two more years before it went up to 21 percent for five years and finally came back down to 20 percent in 2005 - as shown in Figure 3 and Table 1.

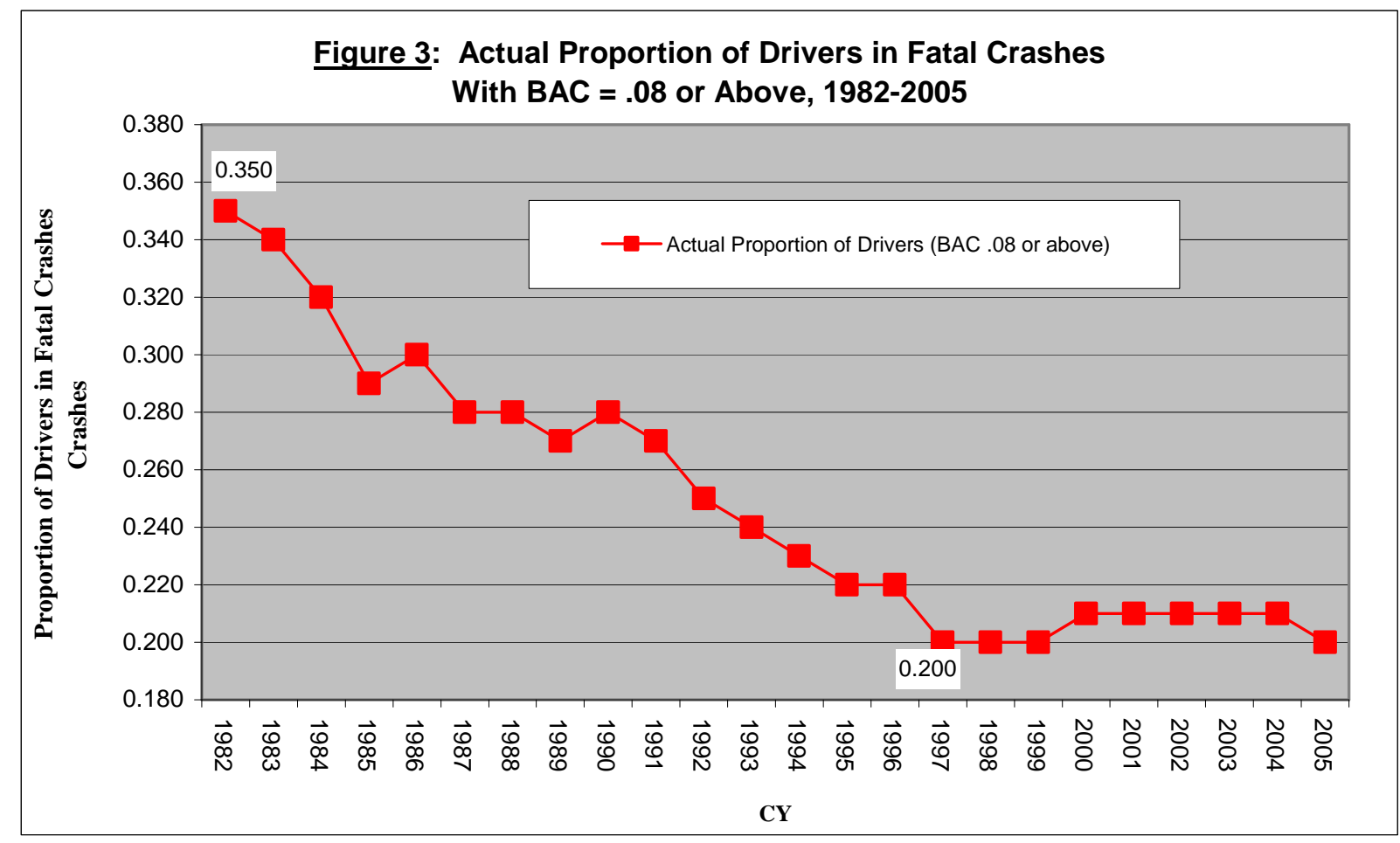

Source: U.S. Department of Transportation, National Highway Traffic Safety Administration, Traffic Safety Facts 2005, p. 34.

\footnotetext{
${ }^{1}$ NHTSA. (2006). Traffic Safety Facts 2005 (NHTSA Technical Report No. DOT HS 810 631, p. 32). Washington, DC: National Highway Traffic Safety Administration.
} 
Table 1: Drivers With BAC $=.08$ or Greater in Fatal Crashes, 1982-2005

\begin{tabular}{|c|c|c|}
\hline \multirow{2}{*}{ Year } & \multicolumn{2}{|c|}{ Drivers in Fatal Crashes } \\
\cline { 2 - 3 } & Total & $\begin{array}{c}\text { Percentage of Drivers With } \\
\text { BAC=.08 or Greater }\end{array}$ \\
\hline 1982 & 56,029 & 35 \\
\hline 1983 & 54,656 & 34 \\
\hline 1984 & 57,512 & 32 \\
\hline 1985 & 57,883 & 29 \\
\hline 1986 & 60,335 & 30 \\
\hline 1987 & 61,442 & 28 \\
\hline 1988 & 62,253 & 28 \\
\hline 1989 & 60,435 & 27 \\
\hline 1990 & 58,893 & 28 \\
\hline 1991 & 54,391 & 27 \\
\hline 1992 & 51,901 & 25 \\
\hline 1993 & 53,401 & 24 \\
\hline 1994 & 54,549 & 23 \\
\hline 1995 & 56,164 & 22 \\
\hline 1996 & 57,001 & 22 \\
\hline 1997 & 56,688 & 20 \\
\hline 1998 & 56,604 & 20 \\
\hline 1999 & 56,502 & 20 \\
\hline 2000 & 57,280 & 21 \\
\hline 2001 & 57,586 & 21 \\
\hline 2002 & 58,113 & 21 \\
\hline 2003 & 58,517 & 21 \\
\hline 2004 & 58,395 & 21 \\
\hline 2005 & 59,104 & 20 \\
\hline
\end{tabular}

Source: U.S. Department of Transportation, National Highway Traffic Safety Administration, Traffic Safety Facts 2005.

During the past two decades, tireless efforts were made through national movements toward legislative enactments (BAC Illegal Per Se laws, administrative licensing revocation (ALR) laws, legal drinking age laws, etc.) to deter alcohol-impaired driving. In addition, many programs that were funded by States, communities, or private organizations were created to reduce alcohol-impaired driving. These alcohol programs and laws served as a general deterrent to all those who drink and drive because they sent a message that the States were getting tougher on impaired driving, and these efforts made people think twice about getting behind the wheel after they had been drinking. In fact, the trend of the proportion of crash fatalities that are alcohol-related - where BAC of 
a crash-involved driver and/or nonoccupant is .01 or higher - is similar to the crash fatality trend where BAC of a crash-involved driver and/or nonoccupant is .08 or above. Furthermore, the trend of the proportion of drivers in fatal crashes with BAC of .01 or higher (Appendix A - Figure A1) is similar to the trend of the proportion of drivers in fatal crashes with BAC of .08 or above.

In 1998, NHTSA sponsored an evaluation by Voas and Tippetts to analyze the "Relationship of Alcohol Safety Laws to Drinking Drivers in Fatal Crashes."2 Three major alcohol safety laws evaluated in that study are: ALR, .08, and .10 BAC Illegal Per Se laws. The study used Fatality Analysis Reporting System (FARS) data to extract information on drivers involved in fatal crashes at two BAC levels - .01 to .09, and .10 or above - for all 50 States and the District of Columbia from 1982 through 1997. Thus, the study was limited to precisely the years where alcohol involvement was steadily decreasing in crashes and before it leveled off. The evaluation also included other factors such as per-capita alcohol consumption and annual vehicle miles traveled that could affect the number of alcohol-related crashes. However, those factors were of secondary importance in the analysis. More importantly, the study did not look at each driver as an individual and it did not extensively control for demographic factors such as driver age and gender. Instead, the study used a single, linear time-trend variable that essentially acted as a surrogate for all these factors; however, such a linear variable would, at least in theory, predict alcohol-impaired driving to decline indefinitely even beyond 1997, and it would be inappropriate to use with datasets extending beyond 1997.

The study by Voas and Tippetts, as well as other studies by Hingson et al., Cucchiaro et al., and Douglas et al., showed statistically significant reductions in the proportion of fatal crashes involving drivers who had been drinking at the time of the crash, after States enacted .08 and .10 BAC Illegal Per Se, ALR, MLDA-21, and/or Zero Tolerance laws. ${ }^{3}$ However, all of these studies analyzed data from years in which alcohol-impaired driving was steadily declining. A question could be raised if the effectiveness attributed to the laws is merely an artifact of a long-term downward trend (that would attribute a "benefit" to almost any measure introduced during those years). The leveling-off of that trend after 1997 offers a new opportunity to see if analyses still attribute significant benefits to the laws even when the overall trend is no longer steadily declining. Therefore, NHTSA has undertaken this update and modification of the Voas/Tippetts analysis, extending it to the 1997-2005 time periods. Specifically, the new study places greater attention on

\footnotetext{
${ }^{2}$ Voas, R.B. and Tippetts, A.S. (1999). The Relationship of Alcohol Safety Laws to Drinking Drivers in Fatal Crashes (NHTSA Technical Report No. DOT HS 808 890). Washington, DC: National Highway Traffic Safety Administration.

${ }^{3}$ Hingson, R., Heeren, T., and Winter, M. (1996). Lowering State Legal Blood Alcohol Limits to 0.08 Percent: The Effect on Fatal Motor Vehicle Crashes, American Journal of Public Health, Vol. 86, No. 9, , 1297-1299.

Cucchiaro, S., Ferreira, J., and Sicherman, A. (1974). The Effect of the 18-Year-Old Drinking Age on Auto Accidents. Cambridge, MA: Massachusetts Institute of Technology, Operations Research Center. Douglass, R.L., Filkins, L.D., and Clark, F.A. (1974). The Effect of Legal Drinking Ages on Youth Crash Involvement. Ann Arbor, MI: University of Michigan, Highway Safety Research Institute.
} 
demographic as well as economic and other external factors that may have not only contributed to the steady decline in 1982-1997 but also influenced the post-1997 trend. Critical factors include driver age, gender, and per-capita alcohol consumption. Let us take a look at some of these factors to see how they might be possible contributors to the overall trend on alcohol-related fatalities in motor vehicle crashes. It is known that the population of the United States has been steadily aging (Appendix A2), and that older people drink less. But it is perhaps not so well known that the shrinkage has not been at a steady rate. This is because the "baby boom" after World War II produced a bulge in the population distribution that aged with each passing year. Figure 4 shows the percent of the United States population that is 18 to 34 years old. ${ }^{4}$ The population age group (18 to 34 years old) shown in Figure 4 decreased at a steady rate from 1982 to 1999 and then gradually leveled off. In 1982, the crest of the "baby-boomers," born in 1947, turned 35 and left their most intensive drinking years behind. By 1999, the last of the baby-boomer generation, born in 1960-1964, had reached 35. The trend in Figure 4 is not so different from the trend in alcohol-related fatalities (Figure 3) that leveled off after 1997. In other words, here is one demographic factor that may partially explain both why the number of fatal crashes involving drivers who had been drinking progressively declined from 1982 to 1997 and why it gradually leveled off around that time.

\footnotetext{
${ }^{4}$ Current Population Reports - Resident Population, By Age and State, 1982-2005. Washington, DC: United States Census Bureau.
} 


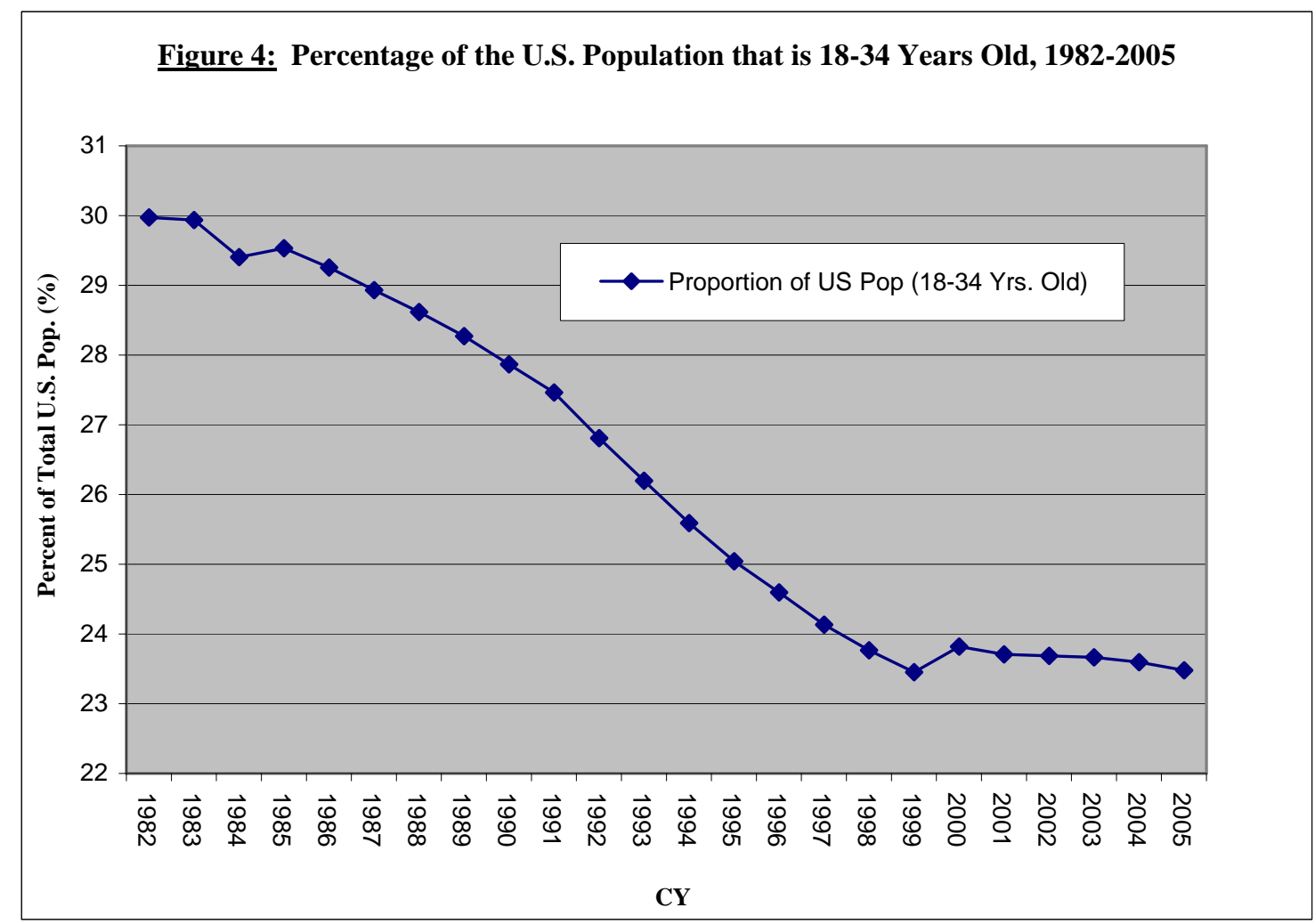

Sources: U.S. Bureau of the Census, Current Population Report - Population by Age and State, 1982-2000. U.S. Census Bureau, "Demographic Profile: Census 2001-2005."

Originally, the majority of licensed drivers were male and, furthermore, even if women had a license, they drove fewer miles per year than males. There has been a long-term trend of more female drivers. Women are less likely to drink and drive than men. ${ }^{5}$ Since the 1980s, there have been more women in the workforce. As a result, more women are driving to work than ever before. Furthermore, with today's hectic lifestyle, even nonworking mothers are more likely to obtain a license and to drive more miles per year than the previous generation. It is perhaps not so well known that the historical trend began to flatten out in the mid-1990s because, by then, women had more or less "caught up" and accounted for half of the driving population. As shown in Figure 5, the percent of licensed drivers that are males declined with time from 52.4 percent in 1983 to 50.3 percent in 1997. ${ }^{6}$ It then leveled off because females had become 50 percent of the drivers. This trend is very similar to the trend in Figure 3 in which the number of

\footnotetext{
${ }^{5}$ NHTSA. (2006). Traffic Safety Facts 2005 (NHTSA Technical Report No. DOT HS 810 631, p. 34). Washington, DC: National Highway Traffic Safety Administration.

${ }^{6}$ NHTSA. (2003). Traffic Safety Facts 2002 (NHTSA Technical Report No. DOT HS 809 620, p. 19). Washington, DC: National Highway Traffic Safety Administration.

NHTSA. (2006). Traffic Safety Facts 2005 (NHTSA Technical Report No. DOT HS 810631 p. 19).

Washington, DC: National Highway Traffic Safety Administration.
} 
fatalities involving drivers with BAC of .08 or above steadily declined and leveled off after 1997. Furthermore, Table 2 shows the average annual miles per licensed driver by gender for calendar years 1983, 1990, 1995, and 2001 as well as the percent change from 1983 to 1995. Average annual miles per licensed driver increased 59 percent for women from 1983 to 1995 but only 19 percent for men. The average annual miles driven did not change much from 1995 to 2001 for either men or women. Although annual mileage is not available on a year-to-year basis, here, too, it seems the trend is similar to Figure 3, with a leveling off somewhere in the mid-1990s. Hence, gender is another demographic factor that may influence the historical alcohol-related driving fatalities trend.

Alcohol is an integral part of many Americans' way of life. Although the percentage of Americans who drink at all has not changed much in the last 30 years, alcohol consumption per capita has declined quite a bit. There is a widespread perception that the public has been placing more emphasis on health, fitness, and safety, especially after 1980. In addition, Federal, State, and local governments, and private organizations have implemented many policies and programs to combat alcohol abuse. One of the many actions taken by governments has been to increase the price of alcoholic beverages through tax increases. However, it is not clear as to whether the impact of tax hikes on alcohol consumption is significant since such increases at a wholesale level (i.e., by gallon, barrel, liter) are calculated to be negligible at a retail level after accounting for the effects of inflation. Thus, the increases would not strongly discourage light and moderate drinkers and certainly not alcohol abusers from purchasing alcohol.

Figure 6 shows that the national per capita beer consumption (in gallons of ethanol) reduced from 1.38 in 1982 to 1.23 in 1995 and then leveled off (more or less). ${ }^{7}$ The trend in Figure 6 once again demonstrates similarity to the trend in Figure 3. According to Gallup's annual Consumption Habits poll, beer has always been the preferred alcoholic beverage for Americans since 1992. ${ }^{8}$ Hence, beer consumption may further explain why the number of alcohol-related fatalities reduced over the fifteen-year period and why it has leveled off. One contributing factor for the lowered beer consumption during this time period is that, as previously discussed, the "baby boom" generation is drinking less after they turn 35 and leave their drinking years behind. Thus, any analysis will need to adjust the trend in per capita consumption for changes in the age of the population. Wine and liquor were neither included in the graph nor the regression analysis because (1) the initial analysis indicated that wine consumption was not significantly associated with the change in the alcohol-related driving trend - although there is a significant shift in wine preferences recorded by Gallup in the last eight years and in 2005, for the first time, wine edged out beer as the standard drink for most Americans, and (2) liquor has consistently ranked third as the preferred drink behind wine and beer.

\footnotetext{
${ }^{7}$ Apparent Per Capita Ethanol Consumption for the United States, 1850-2004, accessible from www.niaaa.nih.gov/databases/qf.htm\#cons.

${ }^{8}$ Jones, J. (July 31, 2006). U.S. Drinkers Consuming Alcohol More Regularly - Beer Regains Slight Edge Over Wine as Preferred Drink. The Gallup Poll News Service, Washington, DC.
} 


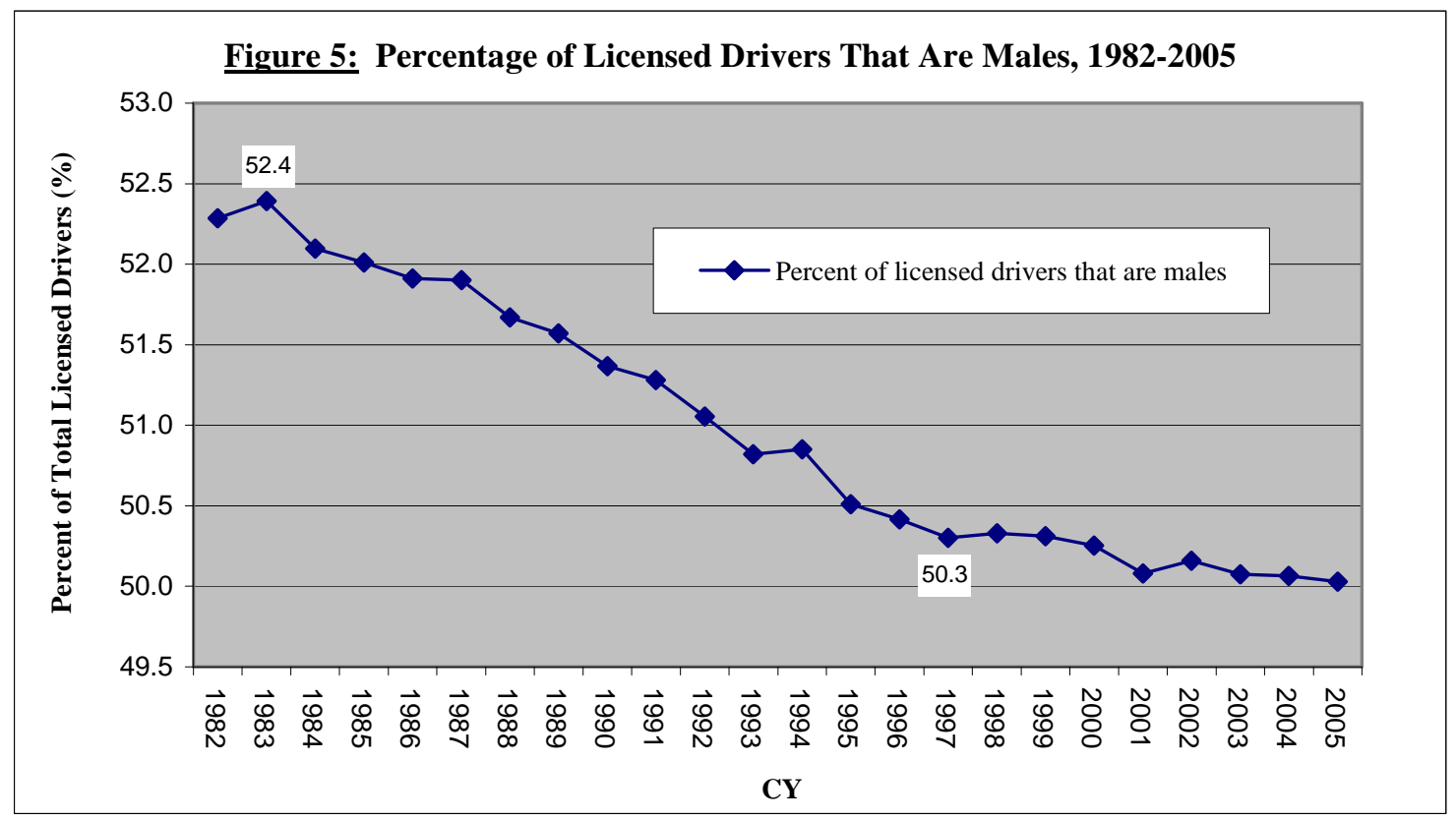

Sources: U.S. Department of Transportation, National Highway Traffic Safety Administration, Traffic Safety Facts, 2002. U.S. Department of Transportation, National Highway Traffic Safety Administration, Traffic Safety Facts, 2005.

Table 2: Average Miles Driven per Licensed Driver by Gender

\begin{tabular}{|l|r|r|r|r|r|}
\hline & $\mathbf{1 9 8 3}$ & $\mathbf{1 9 9 0}$ & $\mathbf{1 9 9 5}$ & $\mathbf{2 0 0 1}$ & $\begin{array}{r}\text { Percent } \\
\text { Change } \\
\text { (1983-1995) }\end{array}$ \\
\hline Male & 13,962 & 16,536 & 16,550 & 16,920 & $\mathbf{1 9}$ \\
\hline Female & 6,382 & 9,528 & 10,142 & 10,233 & $\mathbf{5 9}$ \\
\hline
\end{tabular}

Source: 1983, 1990, 1995 Nationwide Personal Transportation Survey, Federal Highway Administration 2001 National Household Travel Survey, Federal Highway Administration 


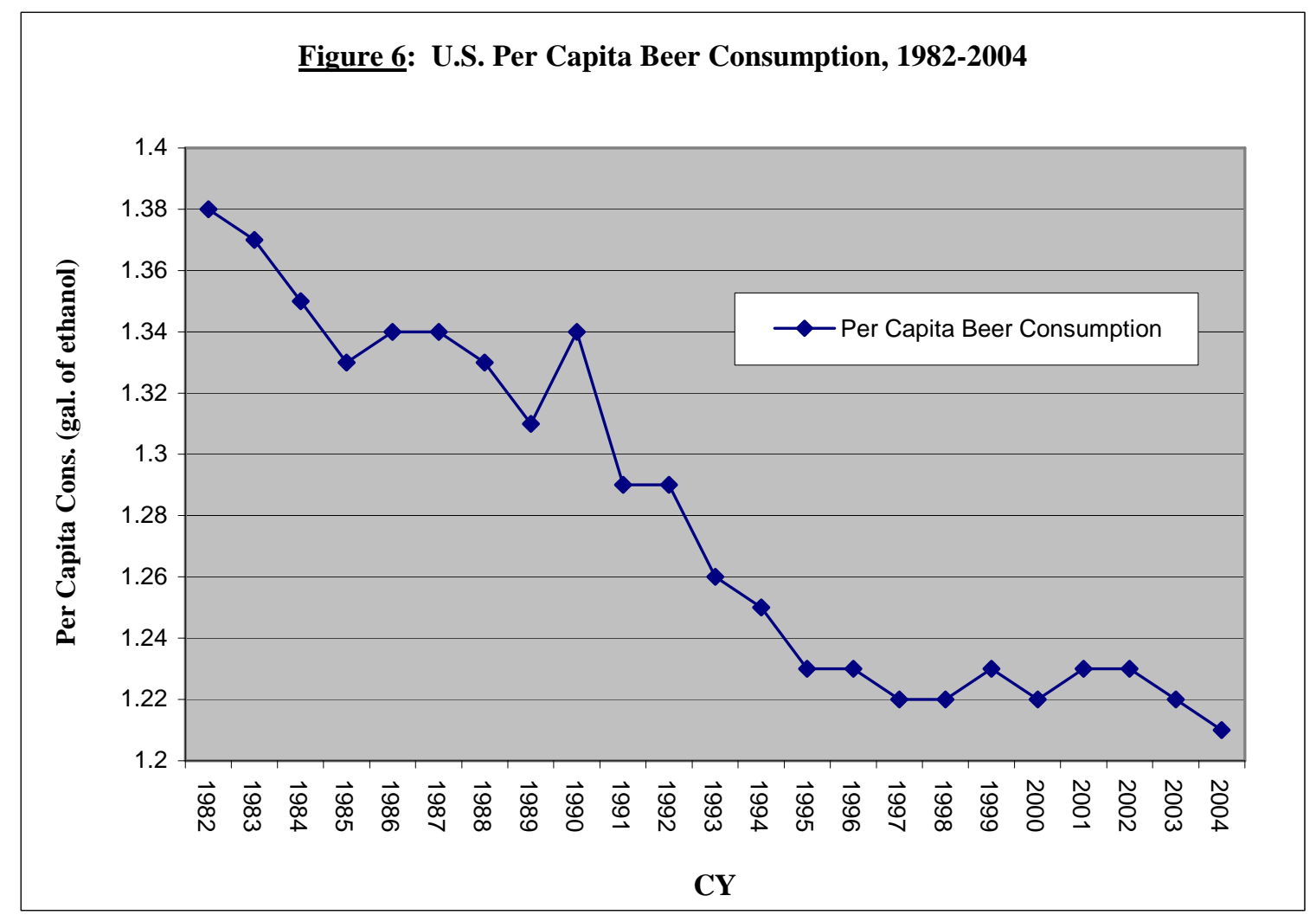

Source: National Institute of Alcohol Abuse and Alcoholism, Division of Epidemiology and Prevention Research, “Apparent Per Capita Ethanol Consumption for the United States, 1850 - 2004”.

http://www.niaaa.nih.gov/Resources/DatabaseResources/QuickFacts/AlcoholSales/consum01.html

Since the early 1980s, tremendous efforts have been made by the States and grassroots organizations such as Mothers Against Drunk Driving (MADD), Students Against Destructive Decisions (SADD) - formerly founded as Students Against Driving Drunk, etc. to combat alcohol-related driving issues by passing new and tougher legislation. Most States in the United States have passed laws making it illegal per se for individuals to have a certain blood alcohol concentration (BAC) while operating a motor vehicle. Studies showed that significant reductions in alcohol-related fatal crashes were found in States that implemented illegal per se laws as well as underage drinking laws. ${ }^{9}$ Laws that

\footnotetext{
${ }^{9}$ Hingson, R.W., Assailly, J.-P., and Williams, A.F. (2004). Underage Drinking: Frequency, Consequences, and Intervention. Traffic Injury Prevention 5(3), pp. 228-236.

Jones, R.K. and Lacey, J.H. (2001). Alcohol and Highway Safety 2001: A Review of the State of Knowledge ( NHTSA Technical Report No. DOT HS 809 383). Washington, DC: National Highway Traffic Safety Administration.

Klein, T.M. (1989). Change in Alcohol-Involved Fatal Crashes Associated with Tougher State Alcohol Legislation (NHTSA Technical Report No. DOT HS 807 511). Washington, DC: Sigmastat, Inc.

Research and Evaluation Associates. (1991). The Effects Following the Implementation of a 0.08 BAC Limit and an Administrative Per Se Law in California (NHTSA Technical Report No. DOT HS 807 777). Washington, DC: National Highway Traffic Safety Administration.
} 
NHTSA considers the following to be effective countermeasures in reducing alcoholimpaired driving: (1) per se laws that define a blood alcohol concentration above a specified threshold as sufficient evidence of "driving under the influence" (namely .10 and .08 BAC per se), (2) laws that provide for administrative license revocation (ALR) or suspension prior to conviction for driving under the influence (also known as "administrative per se" laws), (3) laws that set the minimum legal drinking age to 21 (MLDA-21), and (4) "Zero Tolerance" laws that establish maximum legal BAC limit of .02 for those under 21 years of age while operating a motor vehicle (ZT21).

Figure 7 shows the trend in the number of laws that were in effect for all States including the District of Columbia (51 States) from 1982 to $2005 .{ }^{10}$ Most of these laws were already in effect by 1997 - as evidenced in the figure by the rapid increase from 36 State laws in effect in 1982 versus 204 in 1997 and the subsequent, slower increase to 245 State laws in 2005. Theoretically, if these laws are effective in reducing alcohol-related fatal crashes, then an increase in the number of laws in effect from 1982 to 1997 would translate to a decrease in fatal crashes that are alcohol-related. The reverse of this trend (Figure 7) would look somewhat similar to the alcohol-impaired driving trend in Figure 3. Hence, analyzing alcohol laws may provide further insight and understanding of why the number of fatalities involving drivers who had been drinking steadily declined from 1982 to 1997 and why it leveled off after that.

Wagenaar, A.C., Zobek, T.S., Williams, G.D., et al. (2000). The Effects of DWI Control Efforts: a Systematic Review of the Literature from 1960-1991. Minneapolis, MN: University of Minnesota, School of Public Health.

Zador, P.L., Lund, A.K., Fields, M. and Wienberg, K. (1988). Fatal Crash Involvement and Laws Against Alcohol-Impaired Driving. Washington, DC: Insurance Institute for Highway Safety.

${ }^{10}$ This trend is based on a simple metric of "laws in effect" by calendar year. For example, a score of zero is given if no law is in effect for any State and 255 if all five laws (.10 BAC, .08 BAC, ALR, MLDA-21, and Zero Tolerance) are in effect for 51 States. 


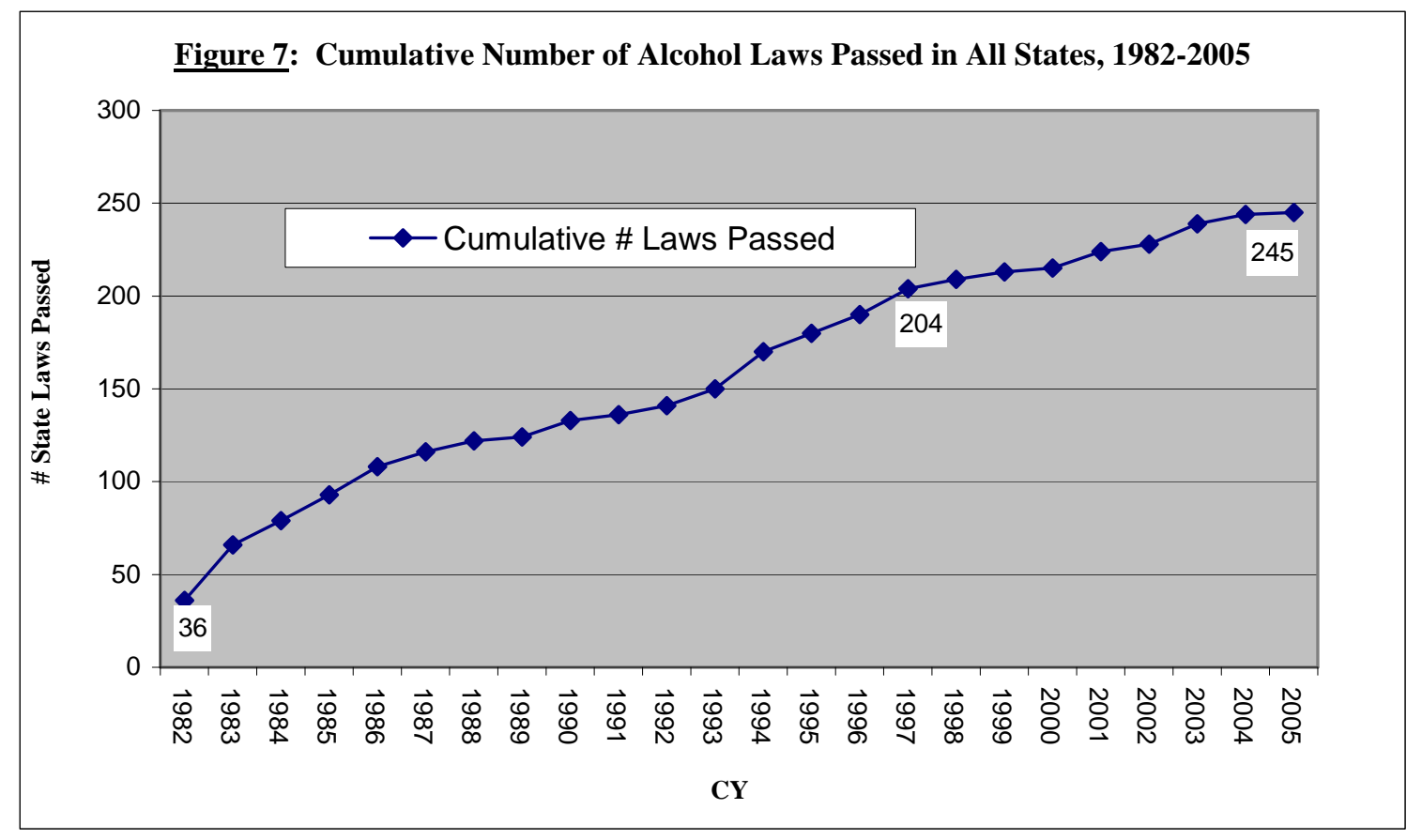

The primary objective of this study is to assess the effects of State laws, alcohol consumption, as well as demographic factors and other external factors that could influence the trend in the proportion of fatal crashes that involved a driver who had been drinking (particularly one with a BAC of .08 or above) - and to find out to what extent these factors explain the declining trend in 1982-1997 and its leveling off in 1998-2005. Other external factors include whether or not the crash occurred: (1) at night, (2) on a weekday, and (3) on a rural roadway. Studies found that alcohol is more prevalent in fatal crashes at night than during the day and more prevalent on weekends than on weekdays. $^{11}$ Alcohol-related fatal crashes could also be more prevalent or less prevalent on roadways with higher speed limits. These factors could influence the proportion of fatal crashes that involved a driver who had been drinking.

As previously discussed, the trend in the proportion of drivers in fatal crashes who had been drinking and had BAC of .01 of higher (Appendix A1) is similar to the trend shown in Figure 3 where drivers involved in fatal crashes had BAC of .08 or above. Thus, it is also worthwhile to determine the effects of these factors on the alcohol-related driving trend (specifically the declining trend in the proportion of drivers in fatal crashes with

\footnotetext{
${ }^{11}$ NHTSA. (2001). Alcohol Involvement in Fatal Crashes 1998 (NHTSA Technical Report No. DOT HS 809103 pp. 5-7). Washington, DC: National Highway Traffic Safety Administration.

NHTSA. (2005). Alcohol Involvement in Fatal Motor Vehicle Traffic Crashes 2003 (NHTSA Technical Report No. DOT HS 809 822, pp. 19-22). Washington, DC: National Highway Traffic Safety Administration,.
} 
BAC of .01 or above from 1982 to 1997 and the leveling off after 1997) and to what extent these factors explain the trend.

The principal analytic tool will be logistic regressions of the probability that a driver involved in a fatal crash had been drinking. Logistic regression allows us to analyze each driver as a separate entity, taking into account the driver's age and gender. In addition, we can take into account (1) what laws were in effect on the day of the crash and (2) the conditions under which alcohol-related fatal crashes are particularly prevalent. 


\section{Method}

In their 1998 analysis, Voas and Tippetts used Klein's imputation method, which was the method being used in FARS at the time of the study, to estimate the BAC of drivers in fatal crashes where alcohol test results were unknown. For those drivers, Klein's technique would calculate the probability that those drivers had a BAC in grams per deciliter (g/dL) of $.00, .01$ to .09 , or .10 and above. ${ }^{12}$ As a result, Voas and Tippetts were able to analyze all drivers in fatal crashes at two different BAC levels (.01 to .09, and .10 or above) since both the imputed and known BAC data are available in all 50 States and the District of Columbia.

\section{Multiple Imputation Method}

Currently, the multiple imputation method is being used in FARS for the same purpose. ${ }^{13}$ Hence, the multiple imputation method for handling missing BAC values was used for all the FARS data (1982-2005) included in this analysis. The difference between the two methods is that the multiple imputation method imputes ten values of BAC for each missing BAC value, whereas Klein's method calculates the probability that a missing BAC value falls within one of the three ranges (.00, .01-.09, or .10 and above). The advantage of using the current method is that it allows the computation of statistics such as variances, measures of central tendency, confidence intervals and standard deviations. With the current procedure, each missing BAC value is replaced with ten simulated values. ${ }^{14}$ However, if the actual BAC is measured and known, all ten values are set to the actual value. The ten imputations, along with the actual BAC values, will first generate ten sets of BAC values (i.e., ten matrices), each of which will then be analyzed separately. The variation obtained from analyzing the ten sets of values will be used to calculate estimates of error attributed to the imputation process. Results from each of the ten sets of BAC values will then be combined by a procedure specified by Rubin to (1) estimate quantities of interest (e.g., proportion of drivers involved in fatal crashes with BAC of .08 or greater) and (2) produce statistical inferences that are valid (e.g., consistent estimation of parameters, accurate calculation of 95 percent confidence intervals, etc.). ${ }^{15}$

\footnotetext{
${ }^{12}$ Klein, T. (1986). A Method for Estimating Posterior BAC Distributions for Persons Involved in Fatal Traffic Accidents ( NHTSA Technical Report No. DOT HS 807 094). Washington, DC; National Highway Traffic Safety Administration..

${ }^{13}$ Subramanian, R. (2002). Transitioning to Multiple Imputation - A New Method to Impute Missing Blood Alcohol Concentration (BAC) Values in FARS (NHTSA Technical Report No. DOT HS 809 403). Washington, DC; National Highway Traffic Safety Administration.

${ }^{14}$ The imputed values are actual values of BAC along the entire plausible range, and can therefore be combined to provide estimates for any defined category of alcohol involvement (i.e., $\mathrm{BAC}=.01+$, $\mathrm{BAC}=.08$, BAC.08+, etc.)

${ }^{15}$ Rubin, D. (1987). Multiple Imputation of Nonresponse in Surveys, J. Wiley and Sons, New York.
} 


\section{Dependent variable}

In estimating the extent of alcohol involvement in fatal crashes, one quantity of interest is the proportion of drivers who were drinking involved in fatal crashes. Many factors that affect fatal crashes are likely to have a similar effect on both non-alcohol and alcoholrelated fatal crashes. For their dependent variable, Voas and Tippetts used the ratio of drivers in fatal crashes with positive BAC test results to drivers in crashes with zero BAC results. Use of this dependent variable automatically controls for factors that have similar influences on all crashes. This study will use essentially the same dependent variable DRV_BAC. This dependent variable will have a value of 1 for drivers with imputed or known BAC values of .08 and greater and a value of 2 for all other drivers. Logistic regression will be used to calibrate the odds that DRV_BAC $=1-$ i.e., the odds that a driver involved in a fatal crash was drinking and had BAC of .08 or above.

\section{Independent variables}

As discussed in the previous chapter "Motivation for This Study," control factors such as driver age, gender, external factors, per-capita alcohol consumption as well as alcoholrelated legislation are all possible contributors to the overall alcohol-related driving trend. Demographic and external variables will be discussed first, followed by detailed discussion of the alcohol consumption and programmatic variables. The following independent variables are obtained directly from FARS or defined for the purpose of the study.

\section{A) Demographic and external variables}

- Gender, expressed as DRVMALE (=1 if the driver is male and 0 if the driver is female).

- The driver's age, expressed as ABS(DRV_AGE-22) ${ }^{16}$ where

1) ABS is the absolute value.

2) 22 is the average driver's age for both males and females with the highest proportion of drivers in fatal crashes who had a BAC of .08 or above.

3) DRV_AGE is the actual age of the driver.

- Day of the week, expressed as WEEKDAY (=1 if the crash occurred on a Monday, Tuesday, Wednesday, Thursday, or Friday and 0 if on a Saturday or Sunday).

- Time of day, expressed as NITE (=1 if 7 p.m. - 5:59 a.m., 0 if 6 a.m. - 6:59 p.m.)

\footnotetext{
${ }^{16}$ Refer to Appendix B for a detailed explanation of the derived formula.
} 
- Roadway function class, expressed as RURAL (= 1 if the crash occurred on a rural roadway and 0 if the crash occurred on an urban roadway).

- Posted speed limit, expressed as SPDLIM55 (=1 if the posted speed limit is 55 75 miles per hour (mph) and 0 if $5-50 \mathrm{mph}$ ).

In this analysis, the dependent variable was modeled as a function of several demographic and external variables. Some of these variables had also been used in deriving the imputed BAC values in FARS. Let us briefly discuss the interrelationships between the model used for imputation and the model used for regression analysis. It is necessary to choose an imputation model that is compatible with the analyses to be performed on the imputed datasets; hence, the imputation model must be robust enough to preserve the associations among variables that will be used later in the investigation. ${ }^{17}$ Thus, there is no need to include the same variables in the latter model since they had already been used in the imputation model - unless their relationships to the dependent variable are of considerable interest - which in this analysis, the demographic and certain external variables are factors that may influence the historical alcohol-related driving fatalities trend. Results pertaining to the dependent variable are not biased by the inclusion of the same variables in the regression model.

\section{B) Adjusted per capita alcohol consumption}

As discussed earlier, for the past 20 years, the trend of the national per capita alcohol consumption - specifically, beer consumption - somewhat mirrors the national alcoholimpaired driving trend. This study will look at per capita ethanol consumption for beer by State and calendar year - to analyze its effects in reducing crash fatalities that involved drivers with a BAC of .08 or above. The national and State per capita ethanol consumption data are obtained from the National Institute of Alcohol Abuse and Alcoholism and computed for the entire population (all age groups). ${ }^{18}$ In reality, alcohol consumption differs significantly due to demographic as well as behavioral changes in the population. In other words, if the population ages over time, or if a State has an olderthan-average population that will lower the overall alcohol consumption, even if consumption stays the same in each age cohort. Thus, consumption data will have to be adjusted in the analysis to reflect different consumption levels by age group by year and by State. Specifically, the 1982-1997 downward trend in actual consumption (Figure 6) is partly due to the aging of the population, and it overstates the actual reduction in consumption for, say, 30-year-olds due to purely behavioral change. Appendix C will discuss in detail the calculation of the adjusted per capita alcohol consumption by State and by year.

\footnotetext{
${ }^{17}$ Rubin, D.B. (1996). Multiple Imputation After 18+ Years (With Discussion). Journal of the American Statistical Association, 91, 473-489.

${ }^{18}$ Per Capita Ethanol Consumption for States, Census Regions, and the United States, 1970-2003, accessible from www.niaaa.nih.gov/databases/qf.htm\#cons.
} 


\section{C) Programmatic independent variables: Alcohol-related legislation}

During the past two decades, many programs were created and laws passed to deter alcohol-impaired driving. In this study, we will look at particularly the passage of the Illegal Per Se, ALR, and drinking age laws to 1) study the immediate effects that these laws had on the general population and 2) explain how they impact the historical alcoholimpaired driving trend.

Let us first discuss in detail each of the laws by 1) defining its function, 2) providing some background information (i.e., legislation efforts, enactment status, etc.), and 3) presenting findings from other studies on the effectiveness of these laws. A separate section identifying the variables (representing the laws) will then follow.

\section{Background information on alcohol laws}

In the early 1980s, approximately three-fourths of the States had passed what are now known as .10 BAC Illegal Per Se laws, and by the mid 1990s, all but two States, Massachusetts and South Carolina, had adopted such laws. ${ }^{19}$ These laws make it illegal for an individual to operate a motor vehicle at or above .10 BAC, essentially making a BAC of .10 or above sufficient evidence that a person was "driving under the influence." During this period, the number of alcohol-impaired fatalities had dropped by 15 percent or more (Figure 3). In 1989, Klein's study concluded that 6 out of 26 States, which implemented the per se laws, experienced significant reductions in the alcohol-impaired driving fatality rate. Most of these States had the .10 BAC limit. ${ }^{20}$ However, many research and epidemiologic findings suggested that a BAC limit of .10 was too lenient and that .08 was a more effective threshold. Utah, Oregon, and Maine were the only three States in the 1980s to reduce their BAC threshold to .08. Great Britain, other countries in Europe, and Australia experienced significant declines in drinking and driving where the BAC limits were set at .08 or $.05 .{ }^{21}$ Dennis et al. conducted an experiment to study the effect of alcohol on individuals' driving abilities by evaluating their handling, judgment, and decision making at various BAC levels $(.00, .03, .07$, and $.11)^{22}$ The results showed a decline in reaction time at a BAC of .11 and progressive declines in both glare recovery time and driving ability as BAC increases. Hingson et al. reported significant reductions in the proportion of fatal crashes involving drivers with

\footnotetext{
${ }^{19}$ Voas, R.B. and Tippetts, A.S. (1999). The Relationship of Alcohol Safety Laws to Drinking Drivers in Fatal Crashes (NHTSA Technical Report Number DOT HS 808 890, p.7). Washington, DC: National Highway Traffic Safety Administration.

${ }^{20}$ Klein, T.M. (1989). Changes in Alcohol-Involved Fatal Crashes Associated with Tougher State Alcohol Legislation (NHTSA Technical Report No. DOT HS 807 094). Washington, DC: Sigmastat, Inc.

${ }^{21}$ Stewart, K. (2000). On DWI Laws in Other Countries (NHTSA Report No. DOT HS 809 037). Washington, DC: National Highway Traffic Safety.

${ }^{22}$ Dennis, M.E. (1995). Effects of Alcohol on Driving Task Abilities. American Drivers and Traffic Safety Education Association - The Chronology, Summer Issue. Indiana, PA.
} 
BAC above .08 when he compared five States that had adopted the .08 threshold with five neighboring States that had kept the .10 threshold. ${ }^{23}$ The strong relationships between BAC levels, increased impairment, and probability of crash involvement have convinced many States to lower their legal BAC limits. ${ }^{*}$ In 2001, the Centers for Disease Control performed a review of the available literature and concluded that the .08 BAC law reduced alcohol-related fatalities by an average of 7 percent. $^{24}$ Currently, all 50 States and the District of Columbia have adopted the .08 threshold. $^{25}$

When coupled with a .08 Illegal Per Se law, administrative license revocation (ALR) sanctions have proven to be one of the most effective ways to deter alcohol-impaired driving. ALR allows police officers to seize the driver's license of individuals who failed a BAC test or refused to submit to a test. Currently, 41 States and the District of Columbia have adopted some form of administrative license revocation. ${ }^{26}$ NHTSA conducted a study in California to determine the effect of implementing .08 Illegal Per Se and ALR laws on alcohol-related fatalities and found a 12-percent reduction when California passed both laws. ${ }^{27}$ Another NHTSA study reported that Illinois, New Mexico, Maine, North Carolina, Colorado, and Utah experienced significant reductions in alcohol-related fatal crashes after the passage of the ALR law in those States. ${ }^{28}$ In an independent study for the Insurance Institute for Highway Safety, researchers found that the number of alcohol involved nighttime fatal crashes was reduced by 9 percent in States that adopted an ALR law relative to States that had not adopted such laws. ${ }^{29}$ It is believed that ALR not only deterred potential offenders, but also deterred convicted/repeat offenders due to its swiftness and certainty. One study found that the recidivism rates decreased by 10 percentage points (15\% to 5\%) for first time offenders and by 18 percentage points (25\% to $7 \%$ ) for multiple offenders. ${ }^{30}$

After the repeal of Prohibition, in an effort to restrict youth access to alcohol, nearly all States designated 21 as the minimum legal drinking age (MLDA). Then, from 1970 to 1975, 29 States lowered the MLDA to $17,18,19$, or $20 .^{31}$ During this period, numerous

\footnotetext{
${ }^{23}$ Hingson, R., Heereen, T., and Winter, M. (1996). Lowering State Legal Blood Alcohol Limits to .08 Percent: The Effect on Fatal Motor Vehicle Crashes. American Journal of Public Health, 86(9), September. * These noted studies are only examples of the many studies on impairment at various BAC levels and on the effectiveness of .08 BAC laws.

${ }^{24}$ Effectiveness of 0.08 Percent Blood Alcohol Concentration (BAC) Laws. CDC Community Guide, 2001.

${ }^{25}$ NHTSA. (2005). Traffic Safety Laws/Facts. Office of Program Development \& Delivery.

${ }^{26}$ NHTSA. (2005). Traffic Safety Laws/Facts. Office of Program Development \& Delivery.

${ }^{27}$ NHTSA. (1991). The Effects Following the Implementation of a 0.08 BAC Limit and an Administrative Per Se Law in California (NHTSA Report No. DOT HS 807 777). Washington, DC: National Highway Traffic Safety Administration.

${ }^{28}$ NHTSA. (1996). State Legislative Fact Sheet.

${ }^{29}$ Zador, P.L., Lund, A.K., Fields, M., and Weinberg, K. (1989). Fatal Crash Involvement and Laws Against Alcohol-Impaired Driving. Washington, DC: Insurance Institute for Highway Safety.

${ }^{30}$ Voas, R.B., Tippetts, A.S., and Taylor, E.P. (1999). Impact of Ohio Administrative License Suspension, Journal of Crash Prevention and Injury Control.

${ }^{31}$ The Minimum Legal Drinking Age: Facts and Fallacies, accessible from www.amaassn.org/ama/pub/article/3566-3640.html.
} 
research findings indicated that motor vehicle crashes, the leading cause of death among teenagers, increased significantly in States where MLDA was lowered. ${ }^{32}$ Armed with such strong evidence (from many studies) linking lower drinking age laws with higher motor vehicle fatalities among youths, 16 States restored their MLDA to 21 between 1976 and 1983. The National Minimum Drinking Age Act of 1984 required all States to raise their minimum purchase and public possession of alcohol age to 21. The Federal Aid Highway Act mandated a reduction of Federal transportation funds to States that had not raised the MLDA to 21. By January 1988, every State had adopted 21 as the MLDA. In 1982, 55 percent of all fatal crashes involving young drivers were alcohol-related when many of the States had minimum drinking ages of 18. Since the National Minimum Drinking Age Act of 1984, the alcohol-related traffic fatality rate has been reduced by half.

The MLDA-21 law was given much credit for the decrease of youth drinking and driving by reducing the availability of alcohol and by establishing the threat of punishment for alcohol use. A subsequent law that further increases the deterrent effect on youth drinking and driving was the Zero Tolerance law. This law makes it illegal for drivers under the age of 21 to operate a motor vehicle with a BAC of .02 or more. Violators of such law have their driver's license suspended or revoked. By 1998, all States and the District of Columbia had adopted this law. In the mid 1990s, Hingson et al. compared 12 States that had enacted the Zero Tolerance law with 12 neighboring States that had not enacted such law in a given pre/post law period and found that single vehicle nighttime crashes among young drivers dropped 16 percent in the zero tolerance States, while the neighboring States had a 1 percent increase. ${ }^{33}$ An early study in Maryland found that alcohol-related crashes for young drivers (ages 21 or less) decreased by 21 percent in six counties after the Zero Tolerance law was implemented. ${ }^{34}$

\footnotetext{
${ }^{32}$ Cucchiaro, S., Ferreira, J., and Sicherman, A. (1974). The Effect of the 18-Year-Old Drinking Age on Auto Accidents. Cambridge, MA: Massachusetts Institute of Technology, Operations Research Center. Douglass R.L., Filkins, L.D., and Clark F.A. (1974). The Effect of Legal Drinking Ages on Youth Crash Involvement. Ann Arbor, MI: University of Michigan, Highway Safety Research Institute. .

Williams, A.F., Rich, R.F., Zador, P.L., and Robertson, L.S. (1974). The Legal Minimum Drinking Age and Fatal Motor Vehicle Crashes. Washington, DC: Insurance Institute for Highway Safety. .

${ }^{33}$ Hingson, R.W. et al. (1994). Lower Legal Blood Alcohol Limits for Young/Drivers. Public Health Reports.

34 Jones, R.K. and Lacey, J.H. (2001). Alcohol and Highway Safety 2001: A Review of the State of Knowledge (NHTSA Technical Report No. DOT HS 809 383). Washington, DC: National Highway Traffic Safety Administration.
} 


\section{Defining variables for the laws}

Table 3 lists the effective dates of the five laws in 50 States and the District of Columbia. ${ }^{35}$ The effective dates are not themselves independent variables in the analysis, but are used to define the independent variables. ${ }^{36}$

The per se laws and ALR laws apply to drivers of all ages. An independent variable PT10 is defined to be

0 if no per se law was in effect on the date of the crash in the State where the crash occurred

1 if a per se law for BAC .10 or lower was in effect on the date of the crash in that State

Similarly, an independent variable PT08 is defined to be

0 if no per se law at all or only a BAC .10 law was in effect on the date of the crash in the State where the crash occurred

1 if a BAC .08 law was in effect on the date of the crash in that State

The variable ALR is defined to be zero if ALR was not in effect in that State on the day of the crash, 1 if it was in effect.

MLDA-21 and Zero Tolerance laws only apply to drivers under the age of 21. Thus, the independent variable MLDA21 is defined to be

0 for any driver age 21 or older

0 for drivers under 21, if the minimum legal drinking age was not 21 on the date of the crash in the State where the crash occurred

1 for drivers under 21, if the minimum legal drinking age was 21 on the date of the crash in that State

The variable ZT21 is defined to be 1 for drivers under age 21 if the Zero Tolerance law was in effect in that State on the day of the crash, 0 for all other drivers.

Once the dependent and independent variables were defined in the SAS datasets, the next steps were to combine the datasets including the imputed BAC values and perform logistic regression analysis. The next several sections discuss in detail the coding analysis procedure.

\footnotetext{
35 Tippetts, A.S. Pacific Institute for Research and Evaluation, an Excel spreadsheet e-mailed to Jennifer Dang on 08/01/03.

${ }^{36}$ Refer to Appendix D for a detailed explanation of how the variables for the laws were defined.
} 


\section{Table 3: Effective Dates of Alcohol Laws in 50 States and DC}

\begin{tabular}{|c|c|c|c|c|c|}
\hline State & $\begin{array}{c}.10 \text { Per Se } \\
\text { Law }\end{array}$ & $\begin{array}{c}\text { Minimum Legal } \\
\text { Drinking Age Law }\end{array}$ & .08 Per Se Law & $\begin{array}{c}\text { Zero Tolerance } \\
\text { Law }\end{array}$ & $\begin{array}{c}\text { Administration } \\
\text { License Revocation } \\
\text { Law }\end{array}$ \\
\hline $\mathbf{A L}$ & 82.00 & 85.75 & $10 / 95$ & $05 / 96$ & $08 / 96$ \\
\hline AK & 83.00 & 84.75 & $09 / 01$ & $11 / 96$ & $10 / 83$ \\
\hline $\mathbf{A Z}$ & 82.50 & 85.75 & $08 / 01$ & $06 / 90$ & $01 / 88$ \\
\hline AR & 83.25 & 82.00 & $08 / 01$ & $08 / 93$ & $07 / 96$ \\
\hline CA & 82.25 & 82.00 & $01 / 90$ & $01 / 94$ & $07 / 90$ \\
\hline $\mathrm{CO}$ & 89.00 & 87.50 & $07 / 04$ & $07 / 97$ & $07 / 83$ \\
\hline $\mathbf{C T}$ & 85.75 & 85.75 & $07 / 02$ & $10 / 95$ & $01 / 90$ \\
\hline DE & 83.25 & 84.00 & $06 / 04$ & $07 / 95$ & $02 / 83$ \\
\hline DC & 83.00 & 86.75 & $04 / 99$ & $05 / 94$ & 55.00 \\
\hline FL & 82.00 & 85.50 & $01 / 94$ & $01 / 97$ & $10 / 90$ \\
\hline GA & 92.00 & 86.75 & $07 / 01$ & $07 / 97$ & $07 / 94$ \\
\hline HI & 83.50 & 86.75 & $06 / 95$ & $12 / 97$ & $07 / 91$ \\
\hline ID & 84.25 & 87.25 & $07 / 97$ & $07 / 94$ & $07 / 94$ \\
\hline IL & 82.00 & 82.00 & $07 / 97$ & $01 / 95$ & $01 / 86$ \\
\hline IN & 83.75 & 82.00 & $07 / 01$ & $01 / 97$ & 09/83 \\
\hline IA & 87.00 & 86.75 & $07 / 03$ & $07 / 95$ & $07 / 83$ \\
\hline KS & 85.50 & 85.50 & $07 / 93$ & $01 / 97$ & $07 / 88$ \\
\hline KY & 92.00 & 82.00 & $10 / 00$ & $10 / 96$ & --- \\
\hline LA & 84.00 & 87.25 & $09 / 03$ & $07 / 97$ & $09 / 84$ \\
\hline ME & 82.00 & 85.50 & $08 / 88$ & $10 / 93$ & $01 / 84$ \\
\hline MD & 90.00 & 82.50 & $09 / 01$ & $05 / 90$ & $01 / 90$ \\
\hline MA & 94.50 & 85.50 & $06 / 94$ & $06 / 94$ & $06 / 94$ \\
\hline MI & 83.25 & 82.00 & $07 / 03$ & $11 / 94$ & --- \\
\hline MN & 82.00 & 86.75 & $09 / 05$ & 06/93 & $09 / 78$ \\
\hline MS & 83.50 & 86.75 & $07 / 02$ & $12 / 98$ & $07 / 83$ \\
\hline MO & 82.00 & 82.00 & $09 / 01$ & $08 / 96$ & 09/83 \\
\hline MT & 83.75 & 87.25 & $04 / 03$ & $10 / 95$ & --- \\
\hline NE & 82.00 & 85.00 & $09 / 01$ & $01 / 94$ & $01 / 93$ \\
\hline NV & 83.50 & 82.00 & $06 / 03$ & $07 / 97$ & $07 / 83$ \\
\hline NH & 83.75 & 85.50 & $01 / 94$ & $01 / 93$ & $07 / 92$ \\
\hline $\mathbf{N J}$ & 83.25 & 83.00 & $01 / 04$ & $12 / 92$ & --- \\
\hline NM & 84.50 & 82.00 & $01 / 94$ & $01 / 94$ & $07 / 84$ \\
\hline NY & 82.00 & 86.00 & $11 / 03$ & $11 / 96$ & --- \\
\hline NC & 82.00 & 86.75 & $10 / 93$ & $09 / 95$ & $10 / 84$ \\
\hline ND & 83.50 & 82.00 & $07 / 03$ & $07 / 97$ & $07 / 83$ \\
\hline $\mathbf{O H}$ & 83.25 & 87.50 & $01 / 04$ & $05 / 94$ & $09 / 93$ \\
\hline OK & 82.50 & 85.75 & $07 / 01$ & $11 / 96$ & $04 / 83$ \\
\hline OR & 82.00 & 82.00 & $10 / 83$ & $07 / 91$ & $07 / 84$ \\
\hline PA & 83.00 & 82.00 & $09 / 03$ & $08 / 96$ & --- \\
\hline $\mathbf{R I}$ & 83.50 & 84.50 & $07 / 00$ & $06 / 95$ & --- \\
\hline SC & --- & 86.75 & $06 / 03$ & $06 / 98$ & $12 / 98$ \\
\hline SD & 82.00 & 88.25 & $07 / 02$ & $07 / 98$ & --- \\
\hline TN & 96.00 & 84.50 & $07 / 03$ & $07 / 93$ & --- \\
\hline TX & 84.00 & 86.75 & $09 / 99$ & $09 / 97$ & $01 / 95$ \\
\hline UT & 82.00 & 82.00 & 08/83 & $07 / 92$ & 08/83 \\
\hline VT & 82.00 & 86.5 & $07 / 91$ & $09 / 97$ & $12 / 89$ \\
\hline VA & 87.00 & 85.50 & $07 / 94$ & $07 / 94$ & $01 / 95$ \\
\hline WA & 82.00 & 82.00 & $01 / 99$ & $07 / 94$ & $01 / 99$ \\
\hline WV & 87.00 & 86.50 & $02 / 04$ & $06 / 94$ & 09/81 \\
\hline WI & 82.25 & 86.75 & $07 / 03$ & $10 / 97$ & $01 / 88$ \\
\hline WY & 90.00 & 88.50 & $07 / 02$ & $07 / 98$ & $07 / 85$ \\
\hline
\end{tabular}

--- denotes data either not available or law not passed at the time of the evaluation. 


\section{D) Other potential independent variables}

We surveyed the literature and where possible performed exploratory analyses with other factors that might have significantly reduced alcohol involvement in fatal crashes.

- Activism of non-government organizations such as MADD and SADD has undoubtedly made the public more aware and less tolerant of the alcohol-impaired driving problem by educating them on crash and injury risks posed by drinking and driving and on the effects of alcohol use and abuse. MADD created the first two chapters in California and Maryland in 1980 and grew to 100 chapters in 1982 to 300 chapters in 47 States in $1984 .{ }^{37}$ Likewise, SADD was founded in Massachusetts in 1981 and created hundreds of chapters throughout nine States in 1982 and many more thereafter. ${ }^{38}$ Moreover, telemarketing programs and other organizations that supported the growth and development of these organizational chapters across the country have promoted tremendous awareness to the general public across all ages of the alcohol-impaired driving issues. Thus, these organizations contributed to the reduction in alcohol-impaired driving in the early 1980s - specifically in 1982-1985. These public information programs and education have (1) provided support and momentum for passing alcohol legislation, (2) increased deterrent effect by educating the public on the provisions and penalties of the laws, and (3) generated public support for law enforcement programs. However, when we investigated quantifying this factor for the analysis (i.e., by counting the number of MADD and SADD chapters by year and by State), we found such information was not readily available.

- Enforcement is obviously an important factor in deterring alcohol-impaired driving. The only quantitative information (by year and State) available to us was the DUI arrest data obtained from the Uniform Crime Reports published yearly by the Federal Bureau of Investigation. ${ }^{39}$ The absolute number of arrests, however, may be an indication of the size of the underlying problem as well as the level of enforcement. More arrests could mean there are more drinkers, or that enforcement was intensified. The number of arrests should be measured relative to the size of the drinking problem.

Aggregate national data initially suggested this could be a promising variable. During the critical years 1982-85, nationwide arrests went up while drunk-driving fatalities sharply decreased, suggesting a trend of stricter enforcement. That encouraged us to define an arrest index for each State and year, normalizing the

\footnotetext{
${ }^{37} \mathrm{http}: / /$ www.madd.org/aboutus/1,1056,1179,00.html

38 http://www.saddonline.com/history.htm

39 http://www.fbi.gov/ucr/cius2006/data/table 69.html
} 
number of arrests relative to aggregate alcohol consumption, and enter it in our model. The arrest index is defined as follows:

$$
\text { Arrest_index } \text { given_year }=100 *\left[\frac{(\text { arrests/alcohol_consumption })_{\text {given_year }}}{(\text { arrests/alcohol_consumption })_{1982}}\right]
$$

However, this independent variable did not have a statistically significant correlation with alcohol-related driving fatalities across our database.

- Sobriety checkpoints also act as deterrents to drivers who drink and remind them and the general public that alcohol-impaired driving is not only socially unacceptable but also a crime. When adequately publicized, they can be very effective. Most States allow sobriety checkpoints, and many States set their own guidelines but still comply with the Federal requirements. Only information such as the year that the States initially permitted sobriety checkpoints was available. We entered that variable in our analysis as another possible measure of enforcement levels. However, it did not have a statistically significant association with our dependent variable.

- Although enforcement and activism (MADD, SADD) could not be directly included as variables in the model, it could be argued that their effect is implicitly present. Parts of the fatality reductions that the model attributes to the various laws is a consequence of the enforcement and publicity activities that have made the laws effective.

- The economy could play a role in the reduction of alcohol-impaired driving where an economic slowdown might, after a while, lead to reduced partying and alcohol consumption, while a resumption of growth could initially increase non-drinking fatalities (work- and shopping-related), lowering the ratio of drinkers to nondrinkers. We obtained a measure of economic activity by State and year ${ }^{\bullet}$ - the Gross State Product per capita - from the Bureau of Economic Analysis and included it in our model. However, neither this variable, nor permutations of it such as a 1-year or 2-year lag, had a significant correlation with our dependent variable.

- Increasing taxes on alcohol could reduce alcohol-impaired driving by discouraging alcohol consumption: directly, by increasing its price and indirectly, by fostering a societal attitude against excessive consumption. It is true that the

- http://www.bea.gov/regional/gsp/action.cfm 
Federal tax on beer was doubled from \$9 to \$18 per 31-gallon barrel in 1991 . However, that amounts to an increase of less than 3 cents per 12-ounce serving. It is unlikely that an increase of 3 cents per can or bottle had much of an effect on drinking and driving. Moreover, to the extent that increased price directly reduces consumption, its effect is already included in our per capita consumption variable.

- One other important safety legislation that was not analyzed in this study is the seat belt laws. The relationship between these laws and drivers in alcohol-related fatal crashes is complex. Historically, drivers who had been drinking at the time of the crash have always had lower belt use than drivers who had not. However, information on belt use by year and by State was not readily available.

\section{Analyzing the multiple-imputed datasets in FARS}

The Multiple Imputation database available at NHTSA and used in this study includes, for each specific driver case on FARS with missing values of BAC, ten predictions of that BAC, based on the non-missing values of other FARS variables for that driver and crash, such as the driver's age and gender, the number of vehicles involved in the crash and the time of day. ${ }^{40}$ The ten predictions are called "imputed" values. If the actual BAC was measured for a driver, that measurement is used for all ten imputed values. Essentially, ten separate copies of FARS are created, identical on all data elements except imputed BAC. The first copy has, on each case, the first imputed value of BAC; the second copy has the second imputed value, and so on.

Any desired statistical analysis, in our case a logistic regression, is performed separately on each of those ten copies of FARS. A SAS procedure MIANALYZE combines and compares the results of these ten separate analyses to create one single set of desired point estimates (in our case, the coefficients for the logistic regression) and confidence bounds for these point estimates that take into account the uncertainty of the drivers' BAC estimate on those cases where it was not actually reported on the original FARS, in addition to the usual sources of uncertainty in the computation of confidence bounds. Appendix E discusses the coding process in detail.

\section{Logistic regression}

Let us discuss further why logistic regression is used in this study. The data points in the regressions are cases of drivers involved in fatal crashes during 1982-2005. As

\footnotetext{
${ }^{40}$ Subramanian, R. (2002). Transitioning to Multiple Imputation - A New Method to Impute Missing Blood Alcohol Concentration (BAC) Values in FARS (NHTSA Technical Report No. DOT HS 809 403). Washington, DC: National Highway Traffic Safety Administration.
} 
previously defined, the dependent variable DRV_BAC has values 1 or 2 . The independent variables were also defined in earlier sections.

The data here do not correspond exactly to the classic "dose-response" model of logistic regression, in which test subjects (e.g., machines) assigned to groups are exposed to varying doses of several harmful agents (e.g., acid, salt, sand, water). Subjects are "failures" if they break down after exposure to the agents, and "successes" if they keep running. Logistic regression calibrates the proportion of failures as a function of the sizes of the doses. Whereas involvements by drivers in fatal crashes with BAC values of .08 or above may readily be considered "failures" in response to "doses" of permissive drinking laws, driver youth, etc., involvements by drivers in fatal crashes with BAC values of .07 or below are hardly "successes" except in an abstract sense that they represent a unit of exposure successfully endured without a per se alcohol-impaired fatality. Nevertheless, NHTSA has successfully applied logistic regression to other data where the dependent variable equaled 1 for a "relevant" crash and 2 for a control-group crash. ${ }^{41}$

Logistic regression uses a large number of individual observations of drinking involvements from drivers with BAC of .08 or above and from those with BAC of .07 or below, comprising a wide variety of actual combinations of the independent variables, to predict the probability of a drinking involvement with a BAC of .08 or above under any hypothetical combination of the independent variables. Specifically, the model generates an equation that expresses the log-odds of a drinking involvement (BAC of .08 or above) as a linear function of the independent variables:

$$
\log \left[\frac{(\text { fatal_crash_involvement })_{B A C=.08 \text { orabove }}}{(\text { fatal_crash_involvement })_{B A C=.07 \text { orbelow }}}\right]=A_{0}+A_{1} * V_{1}+A_{2}+V_{2}+\ldots
$$

A negative coefficient for an independent variable indicates a reduction in drinking involvements with BAC of .08 or above; a positive coefficient indicates an increase. With the exception of certain variables (ABS (DRV_AGE - 22), ADJ_BEER_CONS), all predictor variables evaluated in this study are modeled as dichotomous variables with values set to either " 1 " or " 0 ". For instance, depending on when a law became effective in a given State, the variable represented by that law obtained a value of " 1 ” for all

41 Hertz, E., Hilton, J., and Johnson, D.M. (1995). An Analysis of the Crash Experience of Light Trucks and Vans Equipped with Antilock Braking Systems (NHTSA Technical Report No. DOT HS 808 278).

Washington, DC: National Highway Traffic Safety Administration.

Hertz, E., Hilton, J., and Johnson, D.M. (1995). An Analysis of the Crash Experience of Passenger Cars Equipped with Antilock Braking Systems (NHTSA Technical Report No. DOT HS 808 279). Washington, DC: National Highway Traffic Safety Administration .

Kahane, C.J. (1999). Evaluation of FMVSS 214 - Side Impact Protection: Dynamic Performance Requirement; Phase 1: Correlation of TTI(d) with Fatality Risk in Actual Side Impact Collisions of Model Year 1981-1993 Passenger Cars (NHTSA Technical Report No. DOT HS 809 004). Washington, DC: National Highway Traffic Safety Administration. 
crashes that occurred during the period after the law was in effect and " 0 " for all crashes that occurred during the period prior to the effective date of the law. 


\section{$\underline{\text { Results }}$}

Now, let us assess the effects of alcohol programs plus other factors (i.e., demographic, external, and alcohol consumption) that could explain the decline in alcohol-impaired driving trend - the actual proportion of drivers in fatal crashes with BAC of .08 or above from 1982-1997 and the leveling off from 1998-2005 (Figure 3). First, we will discuss the parameter estimates of the logistic regression model - that is based on a set of independent variables previously discussed as possible significant contributors to the historical alcohol-impaired driving trend from 1982 to 2005. Next, we will (1) see whether the trend predicted by the regression model (specifically the trend of the expected proportion of drivers in fatal crashes with BAC of .08 or above from 1982 to 2005) reproduces the actual trends of declines in alcohol-impaired driving from 1982 to 1997, leveling out after 1997, (2) determine how much of the overall reduction in alcohol-impaired fatalities involving drivers in fatal crashes with BAC of .08 or higher is due to the introduction of laws and how much is due to demographic factors and reductions in alcohol consumption, and (3) estimate the percentage of reduction attributable to specific factors such as individual laws.

Table 4 shows the regression coefficients of all the independent variables considered in the analysis. The positive coefficient (0.6677) of the "gender" variable DRVMALE (equals 1 for male, 0 for female) indicates that male drivers involved in fatal crashes are more likely to be drinking and have BAC at or above a .08 level than females. The negative coefficient (-0.0264) of the driver age factor variable ABS (DRV_AGE - 22) also shown in Table 4 -indicates that the probability of drinking (BAC of .08 or above) is highest at age 22, and it decreases for each year that the driver is older, or younger, than 22. The model also predicts that the likelihood of alcohol involvement in a fatal crash is substantially higher at night than during the day - coefficient estimate of 1.6306 for the variable NITE. It is also higher on a rural roadway than on an urban roadway. Furthermore, the positive coefficient for the adjusted ethanol consumption in beer (ADJ_BEER_CONS) suggests that higher beer consumption will translate to a higher proportion of drivers in fatal crashes with BAC of .08 or higher. As explained in Section B of "Independent Variables," per capita consumption is known only at the State and calendar year level. We know nothing about the drinking habits of the individual drivers involved in the crashes. The variable has already been adjusted for the population's age distribution in the State that year, in order not to "double count" the demographic effects of the aging population.

As for other external factors such as WEEKDAY (equals 1 if occurred on a weekday, 0 on a weekend) and SPDLIM55 (equals 1 if posted speed limit is 55 or greater, 0 otherwise), the model predicts that the probability of an alcohol-impaired fatal crash involvement is lower for a weekday crash than a weekend crash, and also lower on a roadway with posted speed limit of 55 or greater - as shown in Table 4 by the negative coefficients -0.5522 and -0.1295 , respectively. 
As for the alcohol laws, a negative coefficient indicates that the law is beneficial, reducing the proportion of drivers in fatal crashes who had BAC of .08 or above. The analysis method of this report is not ideal for precisely quantifying the benefits of specific laws; for that purpose, more narrowly focused time-series analyses for individual States, before and after the specific law, might be more suitable. Nevertheless, the regression shows a statistically significant benefit (as evidenced by the negative coefficients and significant t-values) for each of the variables PT10, MLDA21, ALR, PT08, and ZT21.

Table 4: Regression Analysis of Demographic, Other External Factors, Adjusted Alcohol Consumption, and Alcohol Laws Variables

\begin{tabular}{|c|c|c|c|c|}
\hline Parameter & Estimate & $\begin{array}{c}\text { Standard } \\
\text { Error }\end{array}$ & $\begin{array}{c}\text { t for H0: } \\
\text { Parameter=Theta0 }\end{array}$ & Pr $>|\mathbf{t}|$ \\
\hline Intercept & -2.2562 & 0.0194 & -116.52 & $<.0001$ \\
\hline DRVMALE & 0.6677 & 0.0075 & 88.66 & $<.0001$ \\
\hline ABS (DRV_AGE-22) & -0.0264 & 0.0003 & -105.37 & $<.0001$ \\
\hline WEEKDAY & -0.5522 & 0.0061 & -90.45 & $<.0001$ \\
\hline NITE & 1.6306 & 0.0063 & 259.20 & $<.0001$ \\
\hline SPDLIM55 & -0.1295 & 0.0059 & -22.08 & $<.0001$ \\
\hline RURAL & 0.3102 & 0.0060 & 52.02 & $<.0001$ \\
\hline ADJ_BEER_CONS & 0.5179 & 0.0147 & 35.26 & $<.0001$ \\
\hline PT10 & -0.1124 & 0.0086 & -13.05 & $<.0001$ \\
\hline MLDA21 & -0.7543 & 0.0103 & -73.29 & $<.0001$ \\
\hline ALR & -0.1027 & 0.0067 & -15.43 & $<.0001$ \\
\hline PT08 & -0.1177 & 0.0071 & -16.48 & $<.0001$ \\
\hline ZT21 & -0.1862 & 0.0150 & -12.42 & $<.0001$ \\
\hline
\end{tabular}

The coefficients shown in Table 4 for the independent variables calibrate a linear relationship between the independent variables and the logarithm of the odds that a driver in a fatal crash was drinking and had BAC of .08 or above. We, however, are less interested in the log odds than in the probability that a driver involved in a fatal crash had a BAC of .08 or above. This probability is derived from our regression - as shown in the equations below: 
$P_{D R V_{-} B A C=1}=Z /(1+Z)$

where

$Z=\exp \left(-2.2562+0.6677 * D R V M A L E-0.0264 * A B S\left(D R V \_A G E-22\right)-0.5522 * W E E K D A Y\right.$

$+1.6306 *$ NITE $-0.1295 *$ SPDLIM 55 + 0.3102*RURAL + 0.5179*ADJ_BEER_CONS

$-0.1124 * P T 10-0.7543 * M L D A 21-0.1027 * A L R-0.1177 * P T 08-0.1862 * Z T 21)$

For any specific driver in FARS, the expected probability that this specific driver had $\mathrm{BAC}>/=.08$ is calculated by entering the values of all the independent variables, for that driver, into the above equations. For example, Table 5 shows what values would be entered if the driver is a 27-year-old male, in Alaska, in 1995, on a rural $55 \mathrm{mph}$ road, at noon, on Sunday.

The expected probability will be a number between 0 and 1 . In our example, the expected probability is 0.3571 . For any group of drivers in FARS, the expected proportion of drivers with $\mathrm{BAC}$ of .08 or above is the average of the individual probabilities. In particular, we are interested in the expected proportion of drivers with BAC of .08 or above among all the drivers of any calendar year. These average proportions, by calendar year, are the trend line predicted by our regression model. Using the PROC MEANS procedure of SAS, the probability of an alcohol-impaired involvement in a fatal crash by calendar year from 1982 to 2005 can then be calculated and graphed accordingly.

Table 5: Values of the Independent Variables Used in the Initial Probability Equation (Example of a 27-year-old male, in Alaska, in 1995, on a rural 55 mph road, at noon, on Sunday)

\begin{tabular}{|l|l|}
\hline Independent Variables & Values \\
\hline DRVMALE & 1 because male \\
\hline ABS (DRV_AGE -22$)$ & $5=$ ABS $(27-22)$ \\
\hline WEEKDAY & 0 because Sunday \\
\hline NITE & 0 because noon \\
\hline SPDLIM55 & 1 because speed limit is 55 \\
\hline RURAL & 1 because rural \\
\hline ADJ_BEER_CONS & $\begin{array}{l}1.40 \text { (adjusted per capita beer consumption in Alaska in } 1995 \text { - see } \\
\text { Appendix C) }\end{array}$ \\
\hline PT10 & 1 because .10 BAC had been in effect since 1983 \\
\hline MLDA21 & 0 because driver is age $21+$ \\
\hline ALR & 1 because ALR had been in effect since $10 / 1983$ \\
\hline PT08 & 0 because .08 BAC did not go into effect until 09/2001 \\
\hline ZT21 & 0 because driver is age $21+$ \\
\hline
\end{tabular}


Figure 8 shows the trend lines of both the expected and the actual proportion of drivers in fatal crashes with BAC of .08 or above from 1982 to 2005. The trends in this figure show that the actual proportion of drivers in fatal crashes with BAC of .08 or above is higher (to some extent) than the expected prior to 1992 and slightly lower (more or less) than the expected after 1992. In general, the average rate of change in the trend line of the actual proportion of drivers in fatal crashes with BAC of .08 or above from 1982 to 1997 is slightly steeper $[(0.350-0.200) / 16=0.009]$ when compared with the rate of change in the trend line of the expected [(0.336-0.216)/16 $=0.008]$ proportion of drivers in fatal crashes with a BAC of .08 or above - also from the same time period. After 1997, the two trend lines level off (more or less) but the expected drinking proportion is more stable than the actual. Overall, our model does a good job tracking the actual even though some of the peaks and outliers are smoothed out. Hence, we can feel quite comfortable using expected effects based on regression formulas to compute the relative contributions of the individual factors.

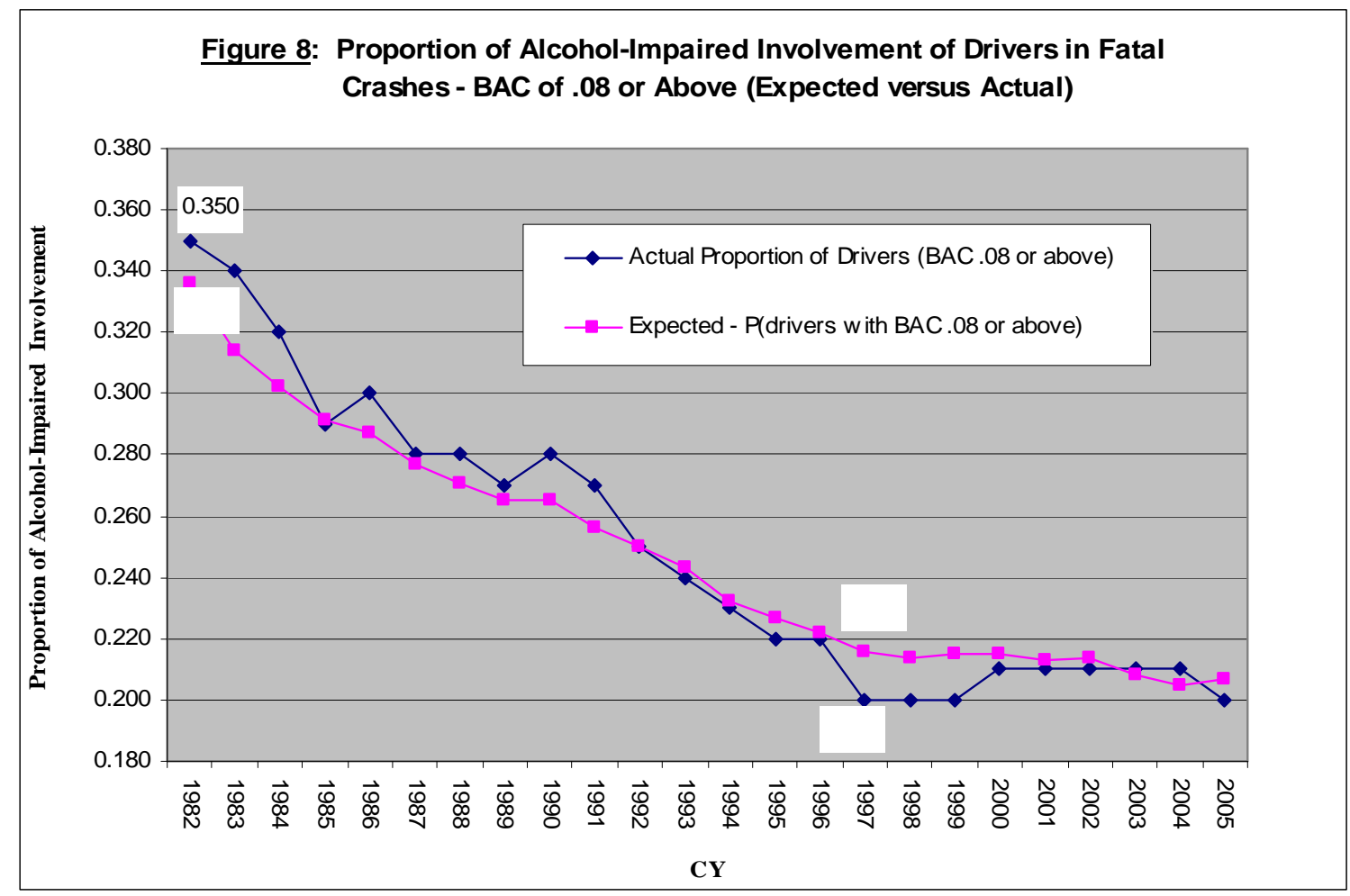

To determine how much of the overall reduction in the proportion of drivers in fatal crashes with BAC of .08 or above is due to demographic, external factors, and alcohol consumption, the values of the alcohol-law variables in the above probability equation are replaced by a new set of values corresponding to the alcohol laws that were in effect on December 31, 1981. Table 6 continues our example of the 27-year-old male in Alaska in 
1995, but now in a hypothetical scenario that alcohol laws were still the same as in 1981. Prior to 1982, none of the studied alcohol laws had been enacted in Alaska. Hence, for this scenario, the values of the individual alcohol-law variables (prior to 1982) are equaled to 0 . In our example, the expected probability of an alcohol-related involvement of a driver with BAC of .08 or above is 0.4428 ; this is higher than the 0.3571 calculated in Table 5 and demonstrates how risk has increased without PT10 and ALR.

Table 6: Values of the Independent Variables Used in the Probability Equation (Controls for Demographic, Environment-related Factors and Alcohol Consumption, But Not the Laws) (Example of a 27-year-old male, in Alaska, in 1995, on a rural 55 mph road, at noon, on Sunday)

\begin{tabular}{|l|l|}
\hline Independent Variables & Values \\
\hline DRVMALE & 1 \\
\hline ABS (DRV_AGE - 22) & 5 \\
\hline WEEKDAY & 0 \\
\hline NITE & 0 \\
\hline SPDLIM55 & 1 \\
\hline RURAL & 1 \\
\hline ADJ_BEER_CONS & 1.40 \\
\hline PT10 & 0 because not in effect in Alaska on 12/31/1981 \\
\hline MLDA21 & 0 because driver is age 21+ \\
\hline ALR & 0 because not in effect in Alaska on 12/31/1981 \\
\hline PT08 & 0 because not in effect in Alaska on 12/31/1981 \\
\hline ZT21 & 0 because driver is age 21+ \\
\hline
\end{tabular}

Similarly, if only the demographic and external factors are considered, then not only are the values of the alcohol-law variables replaced but also the actual year's adjusted per capita ethanol consumption in beer is replaced by the adjusted per capita consumption for Alaska in 1982 - Table 7. In our example, the expected probability of positive BAC (specifically BAC of .08 or above) has further increased to 0.4736 because per capita beer consumption was higher in 1982 than in 1995. 
Table 7: Values of the Independent Variables Used in the Probability Equation

(Controls for Demographic and Environment-related Factors only)

(Example of a 27-year-old male, in Alaska, in 1995, on a rural 55 mph road, at noon, on Sunday)

\begin{tabular}{|l|l|}
\hline Independent Variables & Values \\
\hline DRVMALE & 1 \\
\hline ABS (DRV_AGE - 22) & 5 \\
\hline WEEKDAY & 0 \\
\hline NITE & 0 \\
\hline SPDLIM55 & 1 \\
\hline RURAL & 1 \\
\hline ADJ_BEER_CONS & 1.53 (adjusted per capita beer consumption in AK in 1982) \\
\hline PT10 & 0 \\
\hline MLDA21 & 0 \\
\hline ALR & 0 \\
\hline PT08 & 0 \\
\hline ZT21 & 0 \\
\hline
\end{tabular}

Figure 9 shows the trend lines of the expected proportion of drivers in fatal crashes with BAC of .08 or above from 1982 to 2005 - after controlling for (1) only the demographic and external factors, (2) just the demographic and external factors plus alcohol consumption, and (3) all factors that are considered in the analysis including the alcohol laws. The horizontal line in Figure 9 shows the drinking proportion if (1) the alcohol laws remained unchanged from December 31, 1981, (2) per-capita consumption remained at 1982 levels, and (3) the age and gender distribution of the driving population remained at the 1982 level - that is, nothing had changed since 1982. The three trend lines, in Figure 9, generally show that the expected proportion of drivers in fatal crashes with BAC of .08 or greater reduced substantially from 1982 to 1998 and leveled off after that. Also, as illustrated in the figure, the demographic factors and the alcohol laws each made a sizeable and growing contribution to the overall reduction in alcohol-impaired involvement among drivers in fatal crashes in 1982-1997, but with little or no further growth from 1998 onwards. This will be discussed in depth in the next several sections. 


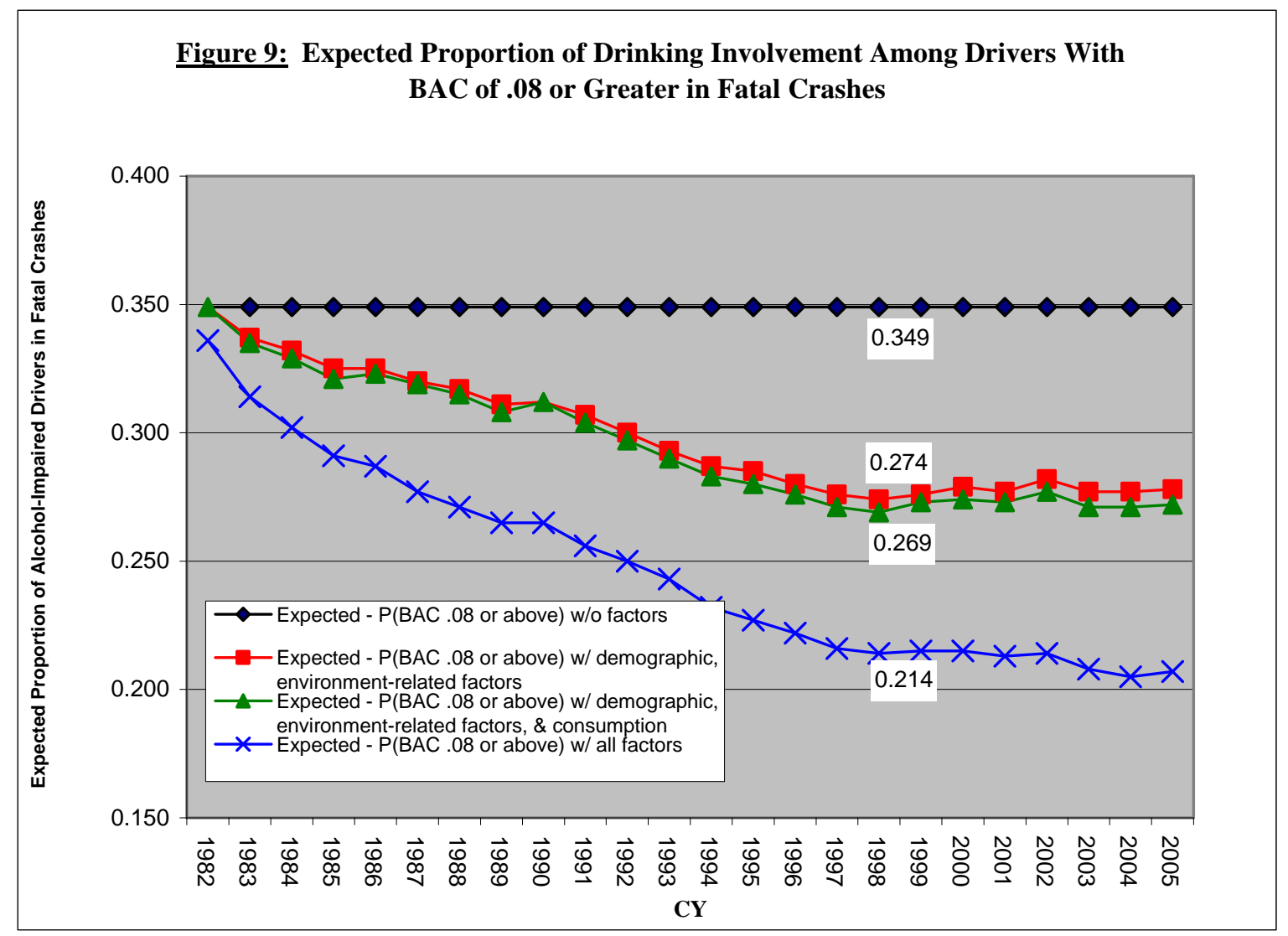

As previously mentioned, in a logistic regression the logarithm of the odds that the dependent variable equals 1 is linearly related to the independent variables. Hence, quantifying the relative effects of individual factors should be based on the log odds ratio so that (1) the effects are additive and commutative and (2) the results are the same regardless of the order the factors are applied to the regression model. The three trend lines in Figure 10 show that the expected log-odds of alcohol-impaired involvement among drivers in fatal crashes reduced substantially from 1982 to 1998 and leveled off after that. As shown by the cross-shaped curve, the expected log-odds of BAC of .08 or above for drivers involved in fatal crashes dropped from -0.623 to -1.301 by 1998 - an overall reduction of 0.678 in the log-odds. The log-odds dropped a little more in 19982005. 


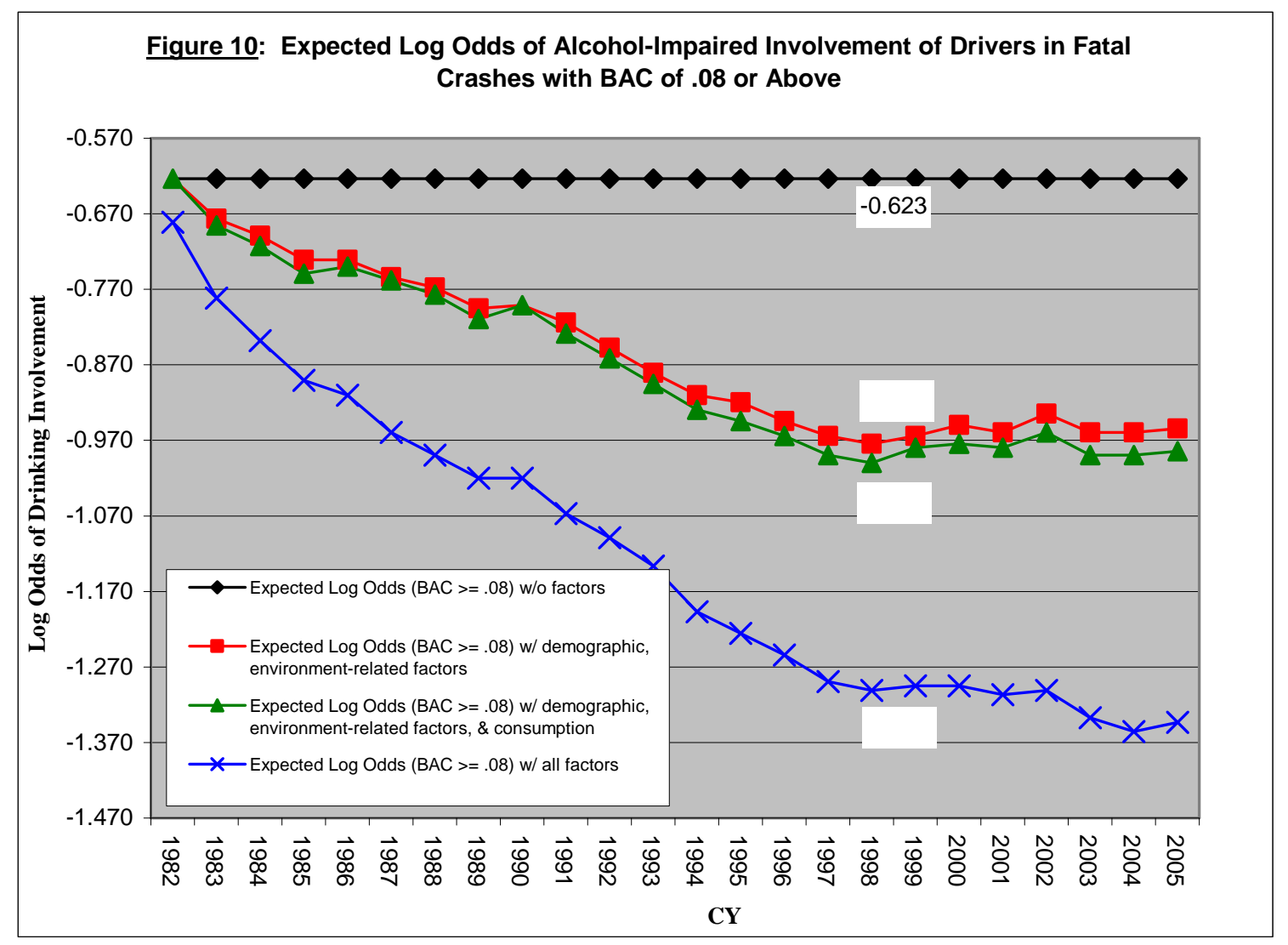

Now let us find out how much of that reduction is explained by driver age and gender; specifically, how much of the reduction is due to the fact that the driving population became older and proportionately more female - and therefore less likely to have been drinking, and by other external factors (particularly day of the week, time of day, roadway function class, and posted speed limit). When we assumed that alcohol laws and per capita alcohol consumption remained the same as in 1982 and modeled only the demographic change, the expected log-odds of drivers in fatal crashes with BAC of .08 or above reduced from -0.623 to -0.974 in 1998, the year with the lowest (more or less) percentage of alcohol-impaired involvement among drivers in fatal crashes, a reduction of 0.351 , as shown in the square-shaped curve. In other words, the aging of the population and the greater proportion of female drivers along with other external factors explained more than one-half $[(0.351) /(0.678)=0.52]$ of the overall decrease in the logodds of alcohol-impaired involvements among drivers in fatal crashes by 1998. This part of the reduction is due simply to demographic changes, and would have presumably occurred even without any programs to discourage drinking and driving. After 1998, the log-odds increased a little as illustrated in Figure 10 by the slight upward trend.

The alcohol consumption variable is conceptually somewhere between the purely "external" demographic variables and the State laws that are directly under the 
government's control. Even though per capita alcohol consumption is certainly not under the direct control of governments, their policies conceivably have a limited effect on per capita consumption to the extent that they influence public attitudes regarding alcohol - it is the aggregate effect of individuals' choices about whether to drink, how often and how much. When the change in per capita beer consumption is taken into consideration, in addition to the demographic effect, the log-odds of an alcohol-impaired involvement, by 1998, decreased from -0.974 on the square shaped curve to -1.000 (as shown on the triangle-shaped curve in Figure 10) - a reduction of 0.026 . Hence, only 4 percent $(0.026$ / 0.678) of the overall reduction is attributed to lower alcohol consumption (specifically beer consumption).

As for the five alcohol laws considered in this analysis, Figure 10 shows the expected log-odds of an alcohol-related involvement among drivers in fatal crashes was reduced by 1998 from -1.000 on the triangle shaped curve to -1.301 on the cross-shaped curve (a reduction of 0.301 ) - when the alcohol laws are included in the analysis along with the demographic factors and alcohol consumption. The laws account for 44 percent $(0.301$ / 0.678) of the overall log-odds reduction. As previously pointed out, the log-odds reduced a little more in 1998-2005.

As shown previously in Figure 7, the number of alcohol laws that were passed in all States steadily increased from 36 in 1982 to 204 in 1997 and the pace of their introduction gradually slowed down after that. The increase from 36 laws in 1982 to 204 in 1997 is a long-term rate of 11.2 new laws per year, actually gaining to 13.5 new laws per year from 1993 to 1997, whereas the subsequent increase from 204 laws in 1997 to 245 laws in 2005 is 5.1 new laws per year. Hence, many of these laws were already in effect by 1997. Indeed, Figure 11 shows that all of these laws except the .08 BAC were in place entirely or largely by 1997 . Three-fourths of the States did not pass the .08 BAC laws until after 1997. Because the majority of their impact is felt in the earlier years, that might explain the substantial reduction in the proportion of alcohol-related involvements among drivers in fatal crashes with BAC of .08 or higher from 1982 to 1998 and the small additional reduction from 1998 to 2005 (specifically after 2002). The aging of the population (specifically the majority of the baby-boomer generation turned 35 by 1998 and left their drinking years behind) and the increased proportion of female drivers (i.e., female drivers accounted for nearly half of the driving population by 1997 and leveled off after that) may further explain the level trend from 1998 to 2005. In fact, the trends from these factors (i.e., demographic and alcohol laws) well depict the national historical alcohol-impaired driving trend before and after 1998. 


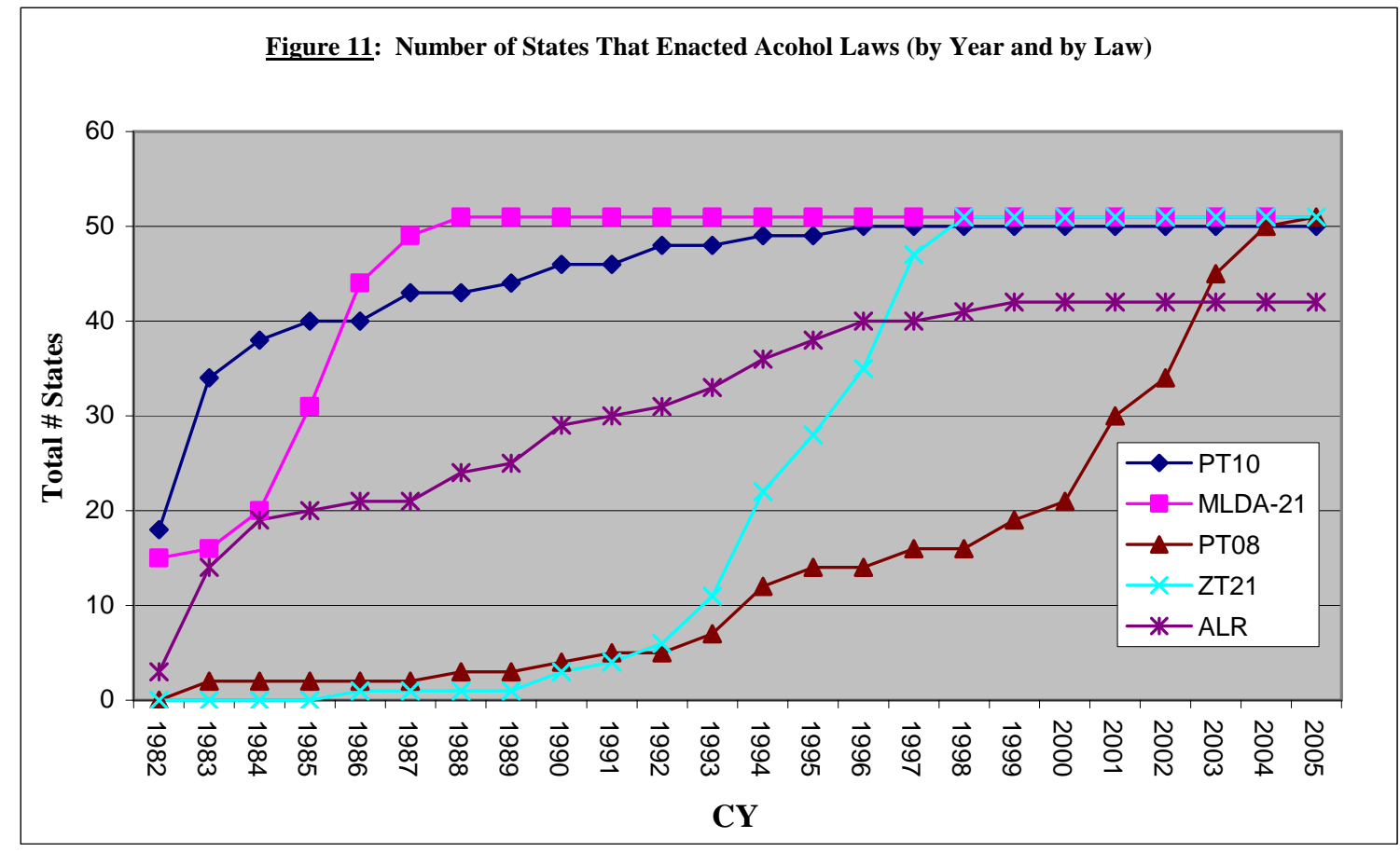

\section{Effects of Individual Laws}

As previously discussed, the analysis method of this report is not ideal for precisely quantifying the benefits of specific laws; for that purpose, more narrowly focused timeseries analyses for individual States, before and after the specific law, might be more suitable. Nevertheless, the regression shows statistically significant benefits for each of the laws. Therefore, it is worthwhile to analyze these laws more in depth by computing the effectiveness of each of the laws, based on the "expected" drinking proportion by drivers involved in fatal crashes (BAC of .08 or above) with and without the law - by comparing two hypothetical scenarios, one of which assumes that all States enacted the law and the other assumes that none of the States enacted the law. These expected probabilities are computed by the regression equation, for two sets of values for the independent variables. The first set of values, corresponding to the first scenario, sets the variable for the law in question to 1 on all cases. The second scenario always sets it to 0 . All the other independent variables are set identically, in the two scenarios, to their original values. For example, Table 8 shows the values of the independent variables used in the probability equation to analyze the effectiveness of the ALR law. 
Table 8: Values of the Independent Variables Used in the Probability Equation To Analyze the Effectiveness of ALR Law

\begin{tabular}{|l|c|c|}
\hline Independent Variables & Without ALR law & With ALR law \\
\hline DRVMALE & Original FARS-derived value & Original FARS-derived value \\
\hline ABS (DRV_AGE_-22) & Original FARS-derived value & Original FARS-derived value \\
\hline WEEKDAY & Original FARS-derived value & Original FARS-derived value \\
\hline NITE & Original FARS-derived value & Original FARS-derived value \\
\hline SPDLIM55 & Original FARS-derived value & Original FARS-derived value \\
\hline RURAL & Original FARS-derived value & Original FARS-derived value \\
\hline ADJ_BEER_CONS & Original value from Appendix D & Original value from Appendix D \\
\hline PT10 & Original value from Table 1 & Original value from Table 1 \\
\hline MLDA21 & Original value from Table 1 & Original value from Table 1 \\
\hline ALR & $\mathbf{0}$ & $\mathbf{1}$ \\
\hline PT08 & Original value from Table 1 & Original value from Table 1 \\
\hline ZT21 & Original value from Table 1 & Original value from Table 1 \\
\hline
\end{tabular}

The averages of the individual expected probabilities with and without the law are then calculated for a full year of FARS data. The overall effectiveness of the law is computed from these two averages by treating the crash involvements among drivers who had BAC of .07 or less as a control group:

$$
\text { Effectiveness }=1-\left\{\frac{P(B A C>=.08)_{\text {law }}}{P(B A C>=.08)_{\text {no_law }}} \div \frac{P(B A C=<.07)_{\text {law }}}{\left.P(B A C=<.07)_{\text {no_law }}\right\}}\right\}
$$

where $P$ is the expected probability of drivers in fatal crashes. The overall effectiveness is the absolute percentage reduction in fatal crash involvements of drivers with BAC of .08 or above.

As shown in Figure 11, the MLDA-21 and .10 BAC per se laws were already in effect in the majority of States by 1988 whereas the other laws were not enacted in most States until later. Hence, crash data from calendar year 1988 were used for the effectiveness analysis of the MLDA-21 and .10 BAC laws. The reason for using 1988 as the baseline year when estimating the effects of these two laws is because the majority of States (if not all) had already passed these laws by 1988 but at the same time only a handful of States had adopted the Zero Tolerance and .08 BAC laws. It does not make much sense to evaluate these two laws in an environment (i.e., crash data from mid-1990s or 2000s) where most States already have the Zero Tolerance and .08 laws. We could have chosen another calendar year as long as the chosen year is before the years when States began to adopt the Zero Tolerance and .08 BAC laws, and the effectiveness estimates for the two laws (MLDA-21 and .10 BAC) would have been similar to those found in 1988.

Theoretically, if a .08 law is in effect, then a $.10 \mathrm{BAC}$ law is implicitly also in effect. Similarly, every State had already enacted MLDA-21 by the time they enacted Zero 
Tolerance. Thus, in these two analyses, the $.10 \mathrm{BAC}$ law is always 1 when the $.08 \mathrm{BAC}$ law is set to 1, and the MLDA-21 law is always 1 when the Zero Tolerance law equals 1. For the effectiveness analysis of the Zero Tolerance, .08 BAC per se, and ALR, calendar year 2005 was used as the baseline year because it is the latest year available and, by 2005 all States had enacted the .08 BAC and Zero Tolerance laws and 42 States had passed the ALR laws.

Table 9 shows that the laws are beneficial in reducing the proportion of drivers in fatal crashes with BAC of .08 or above - as indicated by the positive effectiveness estimates (highlighted in bold). It is estimated that the ALR laws had an 8-percent reduction of fatal crash involvements by drivers with BAC of .08 or above. The introduction of the $.10 \mathrm{BAC}$ laws had a similar impact - as shown by the 9-percent reduction. We also found that the $.08 \mathrm{BAC}$ laws had a 9 percent-reduction in the proportion of drivers (BAC of .08 or above) in fatal crashes. The reductions for these three laws apply to drivers of all ages. As previously discussed, since both MLDA-21 and Zero Tolerance laws were mandated to target youths and to prevent them from drinking and driving until they reach the age of 21, only FARS cases where drivers who are less than 21 years of age are included in the analyses of the two laws - because the laws added no benefits to those ages 21 and older. The effects that these two laws (MLDA-21 and Zero Tolerance) had on drivers ages 20 and under are strong - as demonstrated in Table 9 by the 47 percent and 15 percent reductions of fatal involvements by drivers with BAC of .08 or above. The results found in this study are also comparable to those found in studies previously mentioned in the "Background information on alcohol laws" Section.

Table 9: The Effects of Individual Laws on Drivers With BAC of .08 or Above

\begin{tabular}{|c|c|c|c|c|}
\hline \multirow[t]{2}{*}{ Laws } & \multicolumn{3}{|c|}{$\begin{array}{l}\text { Expected Probability of } \\
\text { Drivers in Fatal Crashes }\end{array}$} & \multirow{2}{*}{$\begin{array}{c}\text { Reduction of Fatal Crash } \\
\text { Involvements by Drivers with } \\
\text { BAC of .08 or Above } \\
(\%)\end{array}$} \\
\hline & Base Year & $\begin{array}{c}\text { BAC of .08 or } \\
\text { Above } \\
\end{array}$ & $\begin{array}{c}\text { BAC of .07 or } \\
\text { below }\end{array}$ & \\
\hline ALR Law & \multirow{2}{*}{2005} & 0.2047 & 0.7953 & \multirow{2}{*}{8} \\
\hline No ALR Law & & 0.2189 & 0.7811 & \\
\hline PT10 & \multirow{2}{*}{1988} & 0.2681 & 0.7319 & \multirow{2}{*}{9} \\
\hline No PT10 Law & & 0.2867 & 0.7133 & \\
\hline PT08 & \multirow{2}{*}{2005} & 0.2065 & 0.7935 & \multirow{2}{*}{9} \\
\hline No PT08 Law & & 0.2233 & 0.7767 & \\
\hline MLDA21* & \multirow{2}{*}{1988} & 0.2403 & 0.7597 & \multirow{2}{*}{$47 *$} \\
\hline No MLDA21 & & 0.3747 & 0.6253 & \\
\hline & \multirow{3}{*}{2005} & & & \\
\hline ZT21* & & 0.1653 & 0.8347 & \multirow{2}{*}{$15 *$} \\
\hline No ZT21 Law & & 0.1893 & 0.8107 & \\
\hline
\end{tabular}

* Analysis limited to drivers younger than 21. 


\section{Analysis of Alcohol-Related Driving Trends Involving Drivers With}

BAC of .01 or Above

As previously mentioned in the "Motivation for This Study" Section, the alcohol-related driving trend (where drivers involved in fatal crashes had BAC of .01 or above) is similar to the alcohol-impaired driving trend where crash-involved drivers had BAC of .08 or above. We have discussed in detail how the effects of alcohol laws, demographic trends, and lower alcohol consumption influenced the impaired driving trend (specifically the proportion of drivers involved in fatal crashes with BAC of .08 or above from 1982 to 2005). It is also worthwhile to analyze similar programs to determine if they have the same effects on drivers involved in fatal crashes with BAC of .01 or above. In other words, we are interested in the general deterrent effects (if any) of these programs on drivers involved in fatal crashes who had been drinking but were not necessarily alcoholimpaired at the time of the crash.

In the latter analysis, we also modeled the effect on a binary dependent variable, but the variable has a value of 1 for drivers with BAC of .01 or above and a value of 2 for all other drivers. The regression coefficients of all the independent variables considered in the latter analysis (shown in Table 10) also indicate that male drivers involved in fatal crashes are more likely to be drinking (BAC of .01 or above) than females. Similar to the previous analysis result, the probability of drinking is highest at age 22, and it decreases for each year that the driver is older, or younger, than 22 - as shown by the negative coefficient. Furthermore, the likelihood of an alcohol-related involvement in a fatal crash is higher (1) at night than during the day and (2) on a rural roadway than on an urban roadway. The results also suggest that higher beer consumption will translate not only to higher proportion of drivers with BAC of .08 or above but also to higher proportion of

drivers with BAC of .01 or above. The model predicts that the probability of a fatal crash involvement by a driver who had BAC of .01 or above is also lower for a weekday crash than a weekend crash, and lower on a roadway with posted speed limit of 55 or greater. Furthermore, the laws are also beneficial in reducing the proportion of drivers in fatal crashes with BAC of .01 or above - though the method of quantifying the benefits of these laws (as previously discussed) may not be appropriate. 
Table 10: Regression Analysis of Demographic, Other External Factors, Adjusted Alcohol Consumption, and Alcohol Laws Variables - BAC of .01 or Above

\begin{tabular}{|c|c|c|c|c|}
\hline Parameter & Estimate & $\begin{array}{c}\text { Standard } \\
\text { Error }\end{array}$ & $\begin{array}{c}\text { t for H0: } \\
\text { Parameter=Theta0 }\end{array}$ & Pr $>|\mathbf{t}|$ \\
\hline Intercept & -1.9582 & 0.0187 & -104.90 & $<.0001$ \\
\hline DRVMALE & 0.6860 & 0.0073 & 94.54 & $<.0001$ \\
\hline ABS (DRV_AGE-22) & -0.0276 & 0.0002 & -129.88 & $<.0001$ \\
\hline WEEKDAY & -0.5941 & 0.0051 & -115.45 & $<.0001$ \\
\hline NITE & 1.6359 & 0.0058 & 284.20 & $<.0001$ \\
\hline SPDLIM55 & -0.1401 & 0.0057 & -24.63 & $<.0001$ \\
\hline RURAL & 0.3083 & 0.0054 & 57.60 & $<.0001$ \\
\hline ADJ_BEER_CONS & 0.5333 & 0.0139 & 38.44 & $<.0001$ \\
\hline PT10 & -0.1224 & 0.0081 & -15.17 & $<.0001$ \\
\hline MLDA21 & -0.6287 & 0.0089 & -70.47 & $<.0001$ \\
\hline ALR & -0.1119 & 0.0060 & -18.50 & $<.0001$ \\
\hline PT08 & -0.1147 & 0.0068 & -16.83 & $<.0001$ \\
\hline ZT21 & -0.2241 & 0.0135 & -16.57 & $<.0001$ \\
\hline
\end{tabular}

Similar to Figure 10, Figure 12 shows the trend lines of the expected log-odds of an alcohol-related involvement of drivers in fatal crashes with BAC of .01 or above after controlling for (1) demographic and external factors (square-shaped curve), (2) demographic factors and alcohol consumption (triangle-shaped curve), and (3) all factors including the alcohol laws (cross-shaped curve). Using the same calculation method previously discussed, demographic changes explained 53 percent of the overall reduction in the proportion of drivers involved in fatal crashes with BAC of .01 or above; lower alcohol consumption accounted for 3 percent, and the remaining 44 percent is attributed to the alcohol laws.

Table 11 shows the effects of individual laws based on the average of the individual expected probabilities of drivers in fatal crashes with BAC of .01 or above, controlling for those with BAC of .00. As expected, the laws are just as beneficial in reducing the proportion of drivers in fatal crashes with BAC of .01 or above as they are with drivers who had BAC of .08 or higher. 


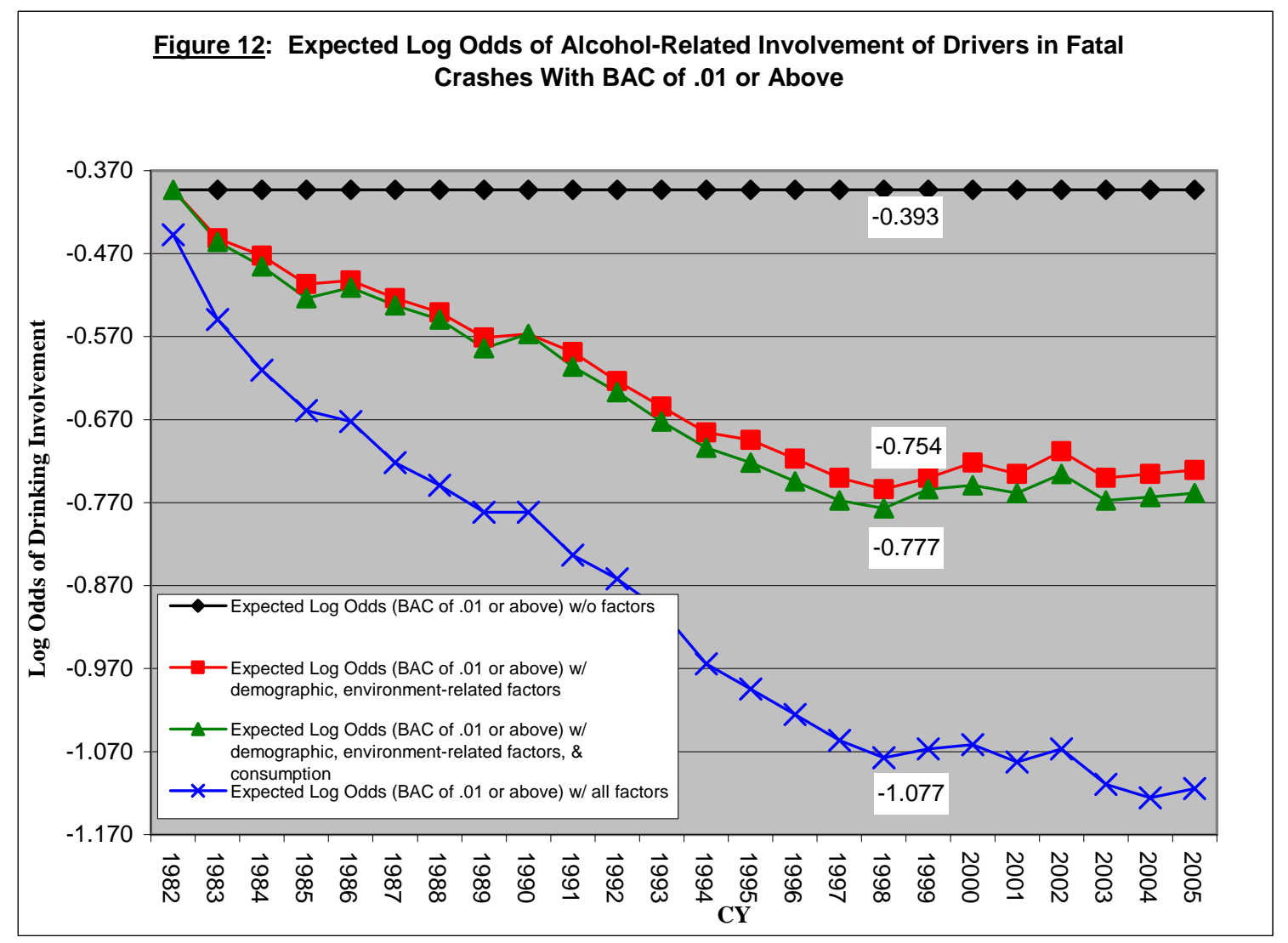

Table 11: The Effects of Individual Laws on Drivers With BAC of .01 or Above

\begin{tabular}{|c|c|c|c|c|}
\hline \multirow[t]{2}{*}{ Laws } & \multicolumn{3}{|c|}{$\begin{array}{l}\text { Expected Probability of } \\
\text { Drivers in Fatal Crashes }\end{array}$} & \multirow{2}{*}{$\begin{array}{l}\text { Reduction of Fatal Crash } \\
\text { Involvements by Drivers } \\
\text { with BAC of .01 or Above } \\
(\%)\end{array}$} \\
\hline & Base Year & BAC of .01 or Above & $\mathrm{BAC}=0$ & \\
\hline ALR Law & \multirow{2}{*}{2005} & 0.2446 & 0.7554 & \multirow[t]{2}{*}{ " } \\
\hline No ALR Law & & 0.2617 & 0.7383 & \\
\hline PT10 & \multirow{2}{*}{1988} & 0.3177 & 0.6823 & \multirow{2}{*}{9} \\
\hline No PT10 Law & & 0.3394 & 0.6606 & \\
\hline & \multirow[b]{2}{*}{2005} & & 0.7532 & \multirow[b]{2}{*}{9} \\
\hline No PT08 Law & & 0.2649 & 0.7351 & \\
\hline & \multirow[b]{2}{*}{1988} & & & \multirow[b]{2}{*}{$40 *$} \\
\hline No MLDA21 & & 0.4317 & 0.5683 & \\
\hline ZT21* & \multirow{2}{*}{2005} & 0.2161 & 0.7839 & \multirow[b]{2}{*}{$18 *$} \\
\hline No ZT21 Law & & 0.2505 & 0.7495 & \\
\hline
\end{tabular}

* Analysis limited to drivers younger than 21. 


\section{Conclusions}

In summary, the change in the alcohol-related driving trends: (1) the proportion of drivers in fatal crashes who had BAC of .08 or above and (2) the proportion of drivers with BAC of .01 or above in fatal crashes, decreasing from 1982 to 1997 and leveling off after 1997, can largely be explained by the following:

- Alcohol laws (44\% of the change)

- The minimum legal drinking age (MLDA-21, Zero Tolerance), .10 BAC, $.08 \mathrm{BAC}$, and ALR laws were very effective in deterring alcohol-related fatal crashes involving drivers who had been drinking at the time of the crash.

- Most of the laws were already in effect in most of the States by 1997. Hence, the majority of the improvements in alcohol-related fatal crash involvements (due to the laws) occurred before 1997. The .08 BAC law is the only law that was passed in a large number of States since 1997. As a result, small additional improvements in alcohol-related crashes occurred after 1997.

- The leveling off by and large after 1997 does not imply that the laws are becoming less effective. On the contrary, they effectively maintain the proportion of drivers involved in fatal crashes who had been drinking.

- Demographic trends (52\% of the change)

- As the driving population became older (specifically the majority of the baby-boomer generation turned 35 by 1998), they tended to drink less and thus, were less likely to be involved in alcohol-related fatal crashes.

- The increasing numbers and annual mileage of female drivers. Female drivers accounted for nearly half of the driving population by 1997 and that proportion did not change after that); females are less likely to drink and drive than males.

- The leveling off of these demographic trends circa 1998 (and even a slight reversal in the trend toward an aging driver population in the last few years) further explains much of the leveling off in the proportion of drivers involved in fatal crashes at all BAC levels. ${ }^{42}$

- Lower per capita alcohol consumption (4\% of the change)

- Although the model predicts a statistically significant reduction in the proportion of drivers in fatal crashes who had been drinking at all BAC levels, the fatality reduction part attributed by the analysis to this factor is substantially less than the effects of the laws and demographic trends.

\footnotetext{
${ }^{42}$ The slight reversal in the aging driver population trend in recent years may explain why the actual proportion of drivers who had been drinking at the time of the crash levels off after 1997 even though there are small additional improvements (due to the .08 BAC per se laws) in alcohol-related crashes after 1997.
} 
- The decrease in per capita alcohol consumption had leveled off by 1997.

In summary, demographics and alcohol laws each explain similar proportions of the overall reduction in alcohol-related fatal crash involvements among drivers with BAC of .08 or above and among those with BAC of .01 or higher. The laws provide similar benefits to those drivers as well. 


\section{REFERENCES}

NHTSA. (2001). Alcohol Involvement in Fatal Crashes 1998 (NHTSA Technical Report No. DOT HS 809 103). Washington, DC: National Highway Traffic Safety Administration.

NHTSA. (2005). Alcohol Involvement in Fatal Motor Vehicle Traffic Crashes 2003 (NHTSA Technical Report No. DOT HS 809 822). Washington, DC: National Highway Traffic Safety Administration.

Apparent Per Capita Ethanol Consumption for the United States, 1850-2004, accessible from www.niaaa.nih.gov/databases/qf.htm\#cons.

Cucchiaro, S., Ferreira, J., and Sicherman, A. (1974). The Effect of the 18-Year-Old Drinking Age on Auto Accidents. Cambridge, MA: Massachusetts Institute of Technology, Operations Research Center.

Current Population Reports - Resident Population, by Age and State, 1982-2005. Washington, DC: United States Census Bureau.

Dennis, M.E. (1995). Effects of Alcohol on Driving Task Abilities. American Drivers and Traffic Safety Education Association - The Chronology, Indiana, PA, Summer Issue.

Douglass, R.L., Filkins, L.D., and Clark, F.A. (1974). The Effect of Legal Drinking Ages on Youth Crash Involvement. Ann Harbor, MI: University of Michigan, Highway Safety Research Institute.

Effectiveness of 0.08 Percent Blood Alcohol Concentration (BAC) Laws. CDC Community Guide, 2001.

Hertz, E., Hilton, J., and Johnson, D. (1995). An Analysis of the Crash Experience of Passenger Cars Equipped with Antilock Braking Systems (NHTSA Technical Report No. DOT HS 808 279). Washington, DC: National Highway Traffic Safety Administration.

Hertz, E., Hilton, J., and Johnson, D. (1995). An Analysis of the Crash Experience of Light Trucks and Vans Equipped with Antilock Braking Systems (NHTSA Technical Report No. DOT HS 808 278). Washington, DC: National Highway Traffic Safety Administration.

Hingson, R.W. et al. (1994). Lower Legal Blood Alcohol Limits for Young/Drivers. Public Health Reports.

Hingson, R.W., Assailly, J.P., and Williams, A.F. (2004). Underage Drinking: Frequency, Consequences, and Intervention. Traffic Injury Prevention 5(3), 228-236. 
Hingson, R., Heeren, T., and Winter, M. (1996). Lowering State Legal Blood Alcohol Limits to 0.08 Percent: The Effect on Fatal Motor Vehicle Crashes. American Journal of Public Health, 86(9), 1297-1299.

History of SADD, accessible from www.saddonline.com/history.htm.

Jones, J. (2006). U.S. Drinkers Consuming Alcohol More Regularly - Beer Regains Slight Edge Over Wine as Preferred Drink. Washington, DC: The Gallup Poll News Service.

Jones, R.K. and Lacey, J.H. (2001). Alcohol and Highway Safety 2001: A Review of the State of Knowledge (NHTSA Technical Report No. DOT HS 809 383). Washington, DC: National Highway Traffic Safety Administration.

Kahane, C.J. (1999). An Evaluation of FMVSS 214 - Side Impact Protection: Dynamic Performance Requirement; Phase 1: Correlation of TTI(d) with Fatality Risk in Actual Side Impact Collisions of Model Year 1981-1993 Passenger Cars (NHTSA Technical Report No. DOT 809 004). Washington, DC: National Highway Traffic Safety Administration.

Klein, T. (1986). A Method for Estimating Posterior BAC Distributions for Persons Involved in Fatal Traffic Accidents (NHTSA Technical Report No. DOT HS 807 094). Washington, DC: National Highway Traffic Safety Administration.

Klein, T.M. (1989). Change in Alcohol-Involved Fatal Crashes Associated with Tougher State Alcohol Legislation. (NHTSA Technical Report No. DOT HS 807 511). Washington, DC: Sigmastat, Inc.

MADD Milestones, accessible from www.madd.org/aboutus/1,1056,1179,00.html.

Per Capita Ethanol Consumption for States, Census Regions, and the United States, 1970-2003, accessible from www.niaaa.nih.gov/databases/qf.htm\#cons.

Percent Reporting Heavy Alcohol Use in the Past Month by Age Group and Demographic Characteristics, NHSDA, 1994-97, accessible from www.niaaa.nih.gov/databases/qf.htm\#dkpat.

Research and Evaluation Associates. (1991). The Effects Following the Implementation of an 0.08 BAC Limit and an Administrative Per Se Law in California (NHTSA Technical Report No. DOT HS 807 777). Washington, DC: National Highway Traffic Safety Administration. 
Rubin, D. (1987). Multiple Imputation of Nonresponse in Surveys. J.Wiley and Sons, New York.

Subramanian, R. (2002). Transitioning to Multiple Imputation - A New Method to Impute Missing Blood Alcohol Concentration (BAC) Values in FARS (NHTSA Technical Report No. DOT HS 809 403). Washington, DC: National Highway Traffic Safety Administration.

Stewart, K. (2000). On DWI Laws in Other Countries (NHTSA Report No. DOT HS 809 037). Washington, DC: National Highway Traffic Safety Administration.

The Effects Following the Implementation of a 0.08 BAC Limit and an Administrative Per Se Law in California (NHTSA Technical Report No. DOT HS 807 777). Washington, DC: National Highway Traffic Safety Administration, 1991.

The Minimum Legal Drinking Age: Facts and Fallacies, accessible from www.amaassn.org/ama/pub/article/3566-3640.html.

Traffic Safety Facts 2002 (NHTSA Technical Report No. DOT HS 810 620). (2003). Washington, DC: National Highway Traffic Safety Administration.

Traffic Safety Facts 2005 (Early Edition) (NHTSA Technical Report No. DOT HS 810 631). (2006). Washington, DC: National Highway Traffic Safety Administration.

Traffic Safety Facts 2005 (Early Edition) (NHTSA Technical Report No. DOT HS 810 631). (2006). Washington, DC: National Highway Traffic Safety Administration.

Voas, R.B. and Tippetts, A.S. (1999). The Relationship of Alcohol Safety Laws to Drinking Drivers in Fatal Crashes (NHTSA Technical Report No. DOT HS 808 890). Washington, DC: National Highway Traffic Safety Administration.

Voas, R.B., Tippetts, A.S., and Taylor, E.P. (1999). Impact of Ohio Administrative License Suspension. Journal of Crash Prevention and Injury Control.

Wagenaar, A.C., Zobek, T.S., Williams, G.D., et al. (2000). The Effects of DWI Control Efforts: a Systematic Review of the Literature from 1960-1991. Minneapolis, MN: University of Minnesota, School of Public Health.

Williams, A.F., Rich, R.F., Zador, P.L., and Robertson, L.S. (1974). The Legal Minimum Drinking Age and Fatal Motor Vehicle Crashes. Washington, DC: Insurance Institute for Highway Safety.

Zador, P.L., Lund, A.K., Fields, M., and Wienberg, K. (1988). Fatal Crash Involvement and Laws Against Alcohol-Impaired Driving. Washington, DC: Insurance Institute for Highway Safety. 
Appendix A 


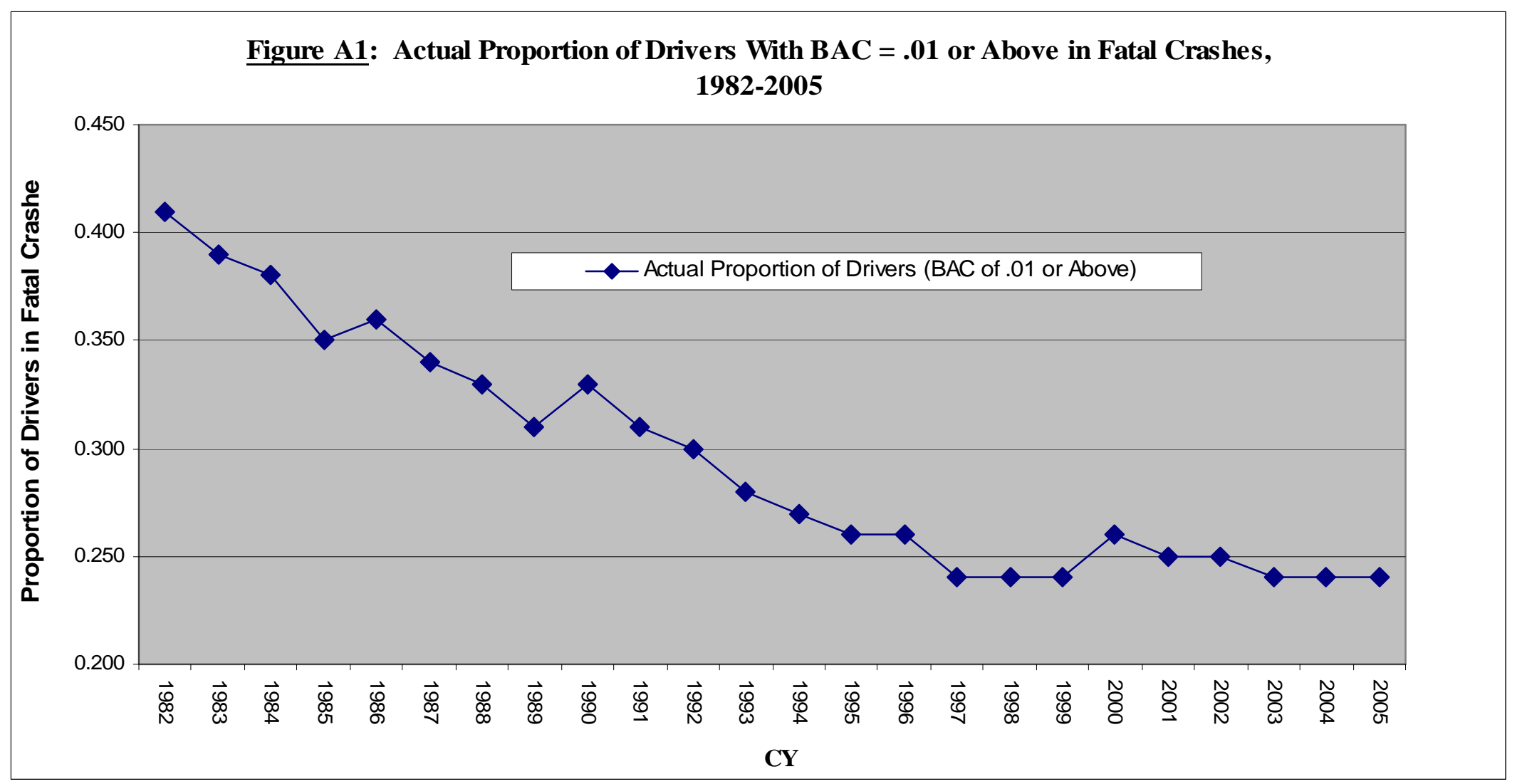




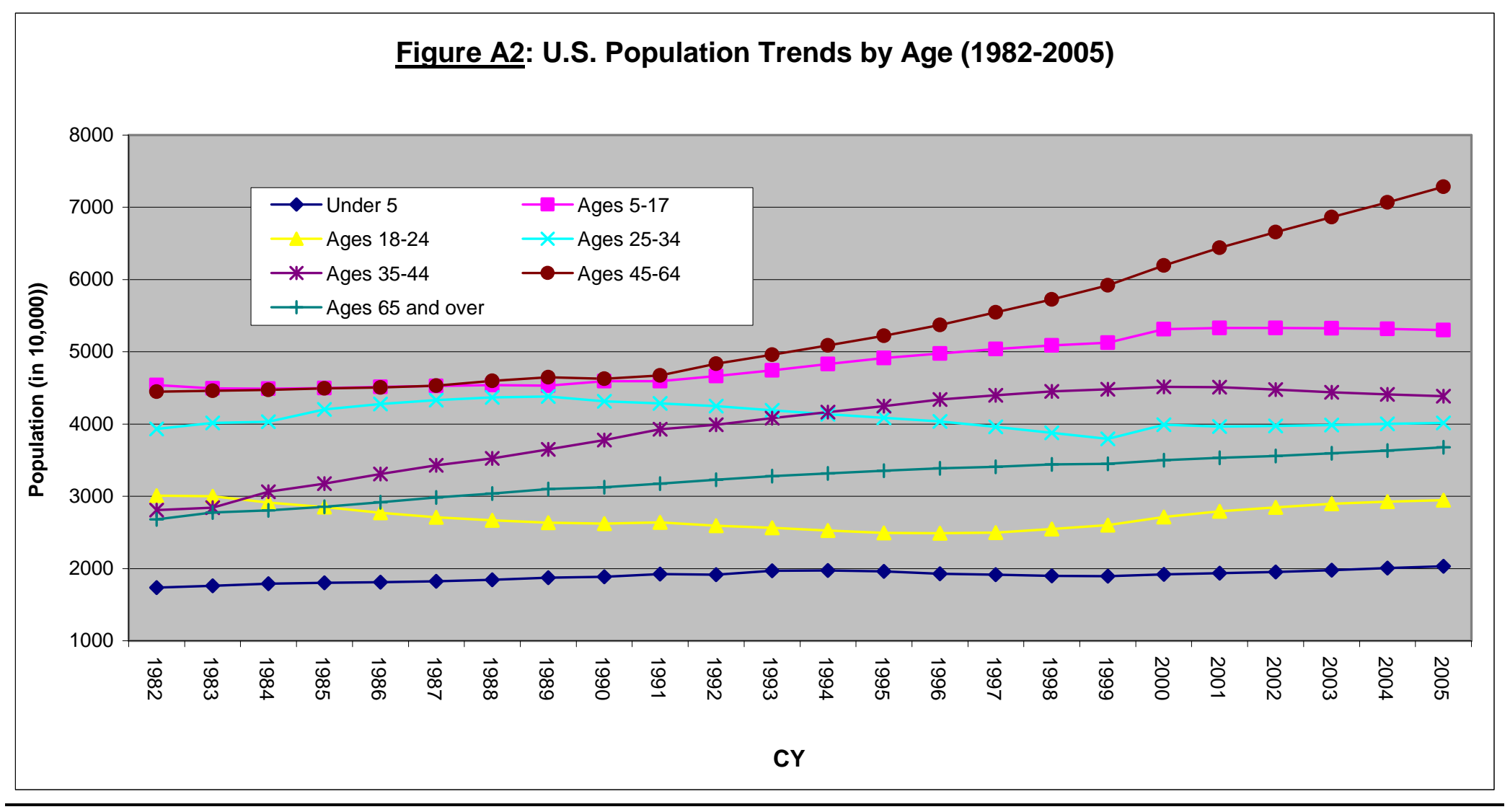




\section{Appendix B}

Figure B1 shows the log odds of drivers ${ }^{43}$ involved in fatal crashes in all 50 States and the District of Columbia by age and gender - ' $\mathrm{M}$ ' for males and ' $\mathrm{F}$ ' for females. As illustrated in the figure, men involved in fatal crashes are generally more likely to have been drinking than women. For men, the drinking proportion increases from age 14 to age 21 and decreases steadily from age 21 onward. For women, the drinking proportion increases from age 14 to age 23 and decreases after age 23. The drinking proportion is at its peak at age 21 for males and 23 for females.

A single independent variable ABS (DRV_AGE - 22) is used to portray the effect of "driver age,"

where,

1) DRV_AGE is the actual age of the driver.

2) Twenty-two is the average of the peak drinking ages for males (21) and females (23).

3) ABS is the absolute value. In other words, ABS (AGE-22) is zero at age 22 and positive on either side of 22.

Figure B2 shows this independent variable as a function of driver age. We can then predict from our regression analysis the probability of a drinking involvement (relative to non-drinking) by drivers in fatal crashes for each year of age above and below 22.

\footnotetext{
${ }^{43} \log$ (drinkers/non-drinkers)
} 
Figure B1: Log Average Drinking Drivers in Fatal Crashes by Age and Gender, 1982-2002

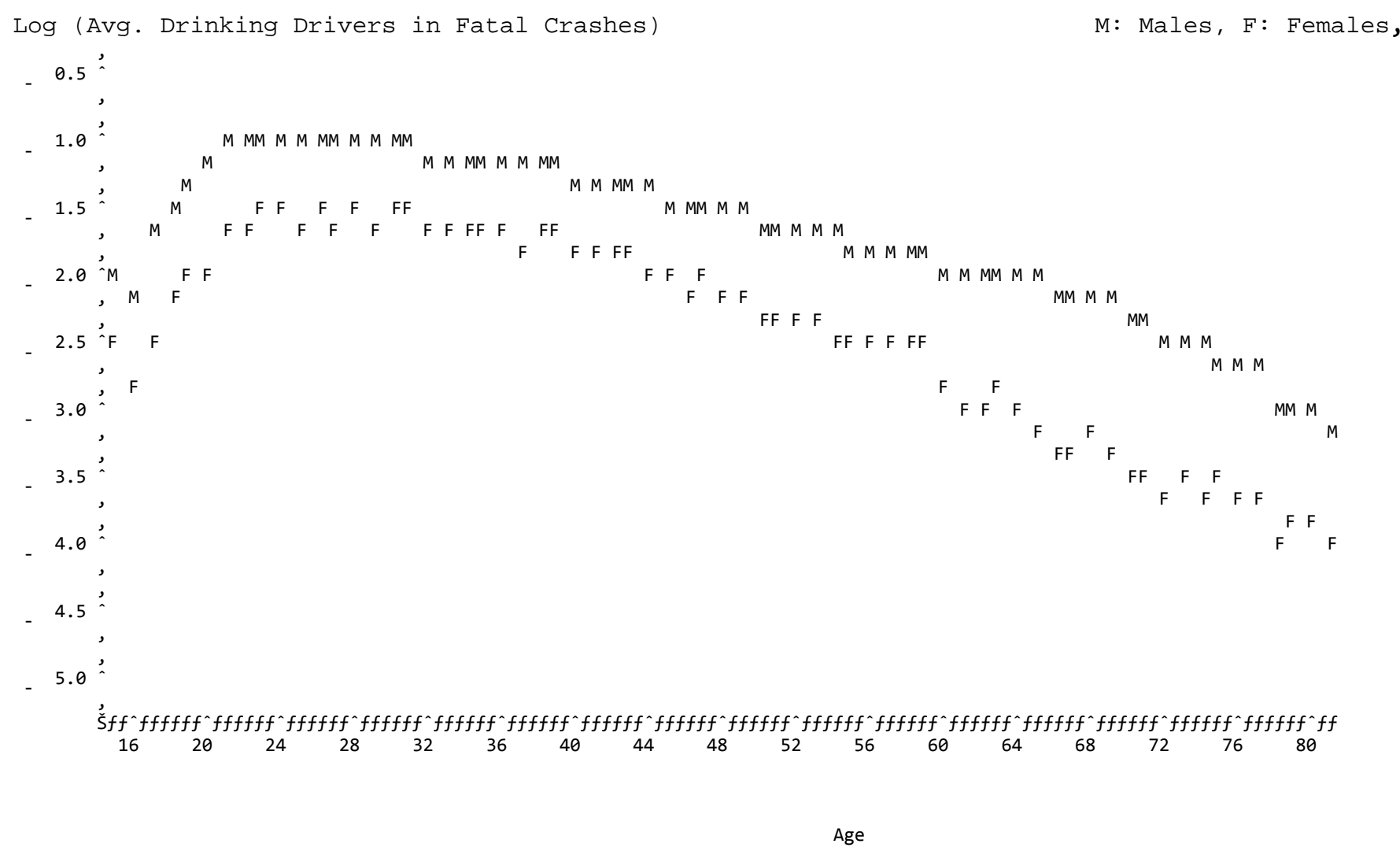




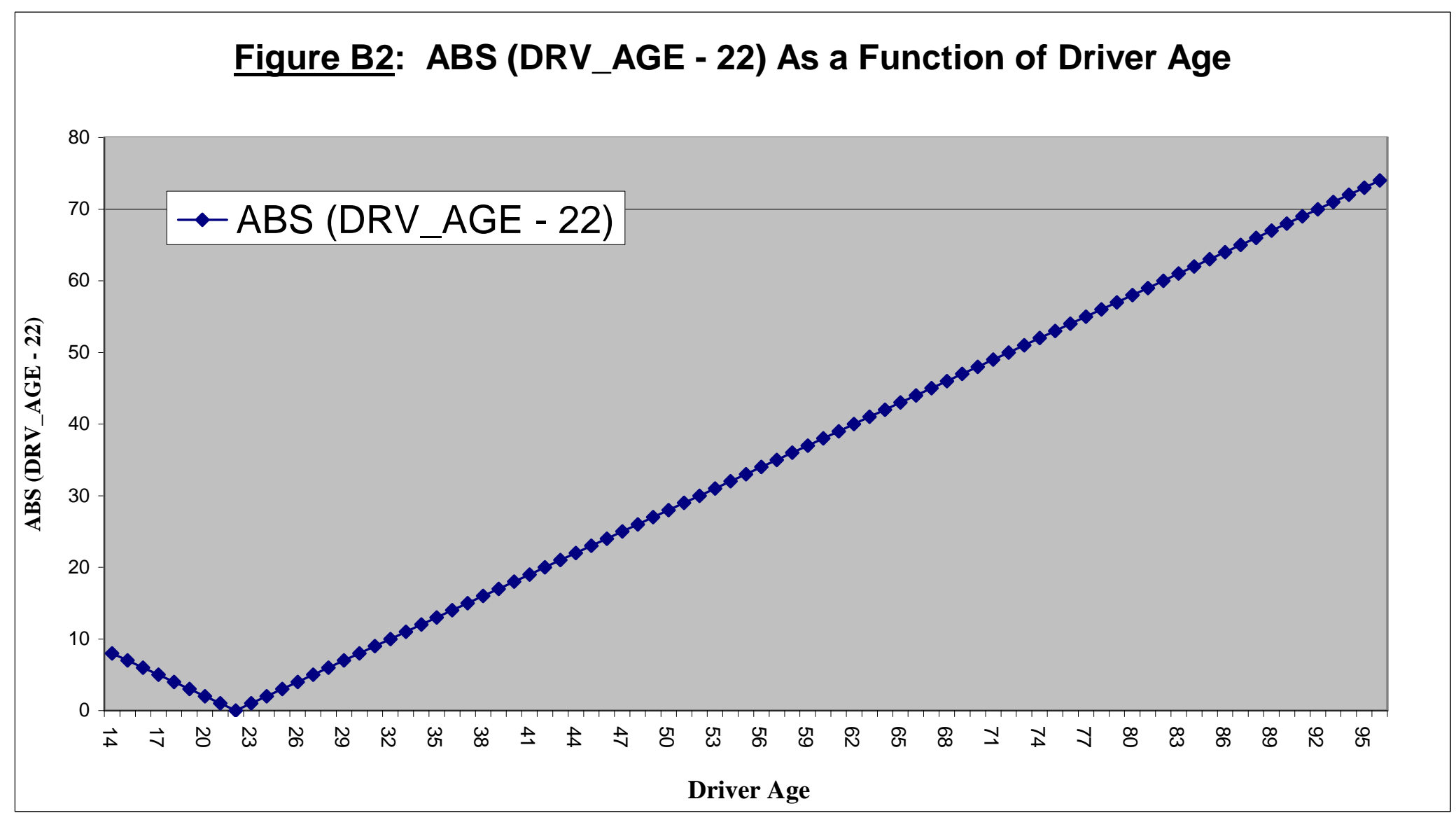




\section{Appendix C}

This section will discuss step-by-step how to calculate the adjusted per capita ethanol consumption (specifically for beer) by State and by year using available population, alcohol consumption, and self-reported drinking data. The adjusted per capita ethanol consumption for beer, expressed as ADJ_BEER_CONS in the analysis, is a continuous variable. To calculate for the values of this variable, both the U.S. and State population by year (1982-2005) and by age group (Under 5, 5-17, 18-24, 25-34, 35-44, 45-64, 65 and up) are obtained from the U.S. Bureau of the Census. ${ }^{44}$ As discussed in the previous section, the U.S. and State per capita ethanol consumption by year are available for the entire population and not for the individual age groups. However, consumption data by age group can be estimated by using the available population data (by age group) and "percent self-reporting heavy alcohol use in the past month" survey data (also by age group) from the National Household Survey on Drug Abuse. ${ }^{45}$ A person who has had at least 5 drinks per occasion on 5 or more days in the past 30 days is considered to be a heavy alcohol user. Since the self-reported drinking data was only available from 1994 to 2002, the average percent is used, and the data had to be extrapolated to estimate the average percent of heavy alcohol users for each of the above-mentioned seven age groups and are shown below:

\begin{tabular}{|c|c|}
\hline Age Group & $\begin{array}{c}\text { Percentage of Population } \\
\text { Who Were Heavy Alcohol } \\
\text { Users (1994-2002 } \\
\text { Average) }\end{array}$ \\
\hline Under age 5 & 0.0 \\
\hline Ages 5-17 & 2.7 \\
\hline Ages 18-24 & 12.8 \\
\hline Ages 25-34 & 7.6 \\
\hline Ages 35-44 & 5.7 \\
\hline Ages 45-64 & 3.8 \\
\hline Over age 64 & 2.2 \\
\hline Entire Population & $\mathbf{4 . 9}$ \\
\hline
\end{tabular}

For example, for the age group 18-24, 12.8 percent of this age group population reported that they had 5 or more drinks per occasion on 5 or more days in the past 30 days.

The following sections continue to discuss step-by-step calculations and provide examples for each of them. First, the proportion of the population by age group is calculated by dividing the population of each age group by the total population. Total population is the sum of the population of all the age groups (Example 1).

${ }^{44}$ Current Population Reports - Resident Population, By Age and State, 1982-2005. Washington, DC: United States Census Bureau.

45 Percent Reporting Heavy Alcohol Use in the Past Month by Age Group and Demographic Characteristics, NHSDA, 1994-1997, accessible from www.niaaa.nih.gov/databases/qf.htm\#dkpat. 
$\underline{\text { Example 1: }}$ State $=$ Alaska, Year $=1995$

\begin{tabular}{|c|c|c|c|c|c|c|c|c|}
\hline & Under 5 & $\mathbf{5 - 1 7}$ & $\mathbf{1 8 - 2 4}$ & $\mathbf{2 5 - 3 4}$ & $\mathbf{3 5 - 4 4}$ & $\mathbf{4 5 - 6 4}$ & $\mathbf{6 5}$ \& up & Total \\
\hline $\begin{array}{c}\text { AK Population } \\
(000)\end{array}$ & 53 & 136 & 62 & 91 & 116 & 115 & 30 & 603 \\
\hline Proportion of AK total population & 0.0879 & 0.2255 & 0.1028 & 0.1509 & 0.1924 & 0.1907 & 0.0498 & 1.0000 \\
\hline
\end{tabular}

The percentage of the population (for each age group) is multiplied by the estimated 1994-2002 U.S. average percentage of alcohol users for that age group. If Alaska in 1995 had the same rates of heavy drinking in each age group as the national average for 19942002, the percent of the total population expected to be heavy users based on their age is the sum of the proportion of users of all the age groups - in bold and highlighted in gray in Example 2.

\title{
Example 2: State $=$ Alaska, Year $=1995$
}

\begin{tabular}{|c|c|c|c|c|c|c|c|c|}
\hline & Under 5 & $\mathbf{5 - 1 7}$ & $\mathbf{1 8 - 2 4}$ & $\mathbf{2 5 - 3 4}$ & $\mathbf{3 5 - 4 4}$ & $\mathbf{4 5 - 6 4}$ & $\mathbf{6 5}$ \& up & Total \\
\hline Proportion of AK total population & 0.0879 & 0.2255 & 0.1028 & 0.1509 & 0.1924 & 0.1907 & 0.0498 & 1.0000 \\
\hline Avg. proportion of heavy users & 0 & 0.027 & 0.128 & 0.076 & 0.057 & 0.038 & 0.022 & \\
\hline $\begin{array}{c}\text { Proportion of AK population } \\
\text { expected to be heavy users based on their age }\end{array}$ & 0 & 0.0061 & 0.0132 & 0.0115 & 0.0110 & 0.0072 & 0.0011 & $\mathbf{0 . 0 5 0 1}$ \\
\hline
\end{tabular}

In other words, because the population of Alaska in 1995 is younger than the population of the United States in 1994-2002, we would expect a slightly higher percentage of heavy drinkers, 5.01 rather than 4.85, even if Alaskans had the same per capita consumption as other Americans of the same age. The ratio of these two percentages is used to ageadjust the per capita consumption - Example 3.

\section{Example 3:}

\author{
Given: State $=$ Alaska \\ Year $=1995$ \\ Alaska unadjusted per capita consumption (gallons of ethanol in beer) in $1995=1.45$
}

$\underline{\text { Result: }}$
Alaska 1995 expected proportion of heavy drinkers: 0.0501
U.S. 1994-2002 actual proportion of heavy drinkers: 0.0485
Alaska adjusted per capita consumption in 1995: $1.45(0.0485 / 0.0501)=1.40$

In other words, if Alaskans in 1995 had the same age distribution as the United States in 1994-2002, their per capita alcohol consumption would have been only 1.40, not 1.45. The alcohol consumption was as high as 1.45 because many Alaskans were young (in their prime drinking years). 


\section{Appendix D}

Numeric variables were used and separately defined to represent the months and the years for each of the laws (Table C-1). Since most of the States passed the .10 BAC and Minimum Legal Drinking Age 21 (MLDA-21) laws during the 1980s and since information on the exact months the laws took effect were no longer readily available, the months had to be estimated based on information obtained from the old annual NHTSA legislation compendia and from other sources. Thus, the dates used for the two laws are estimates of which quarter within the passage year the laws took effect (only the months are estimated, the years are not). The decimals $.00, .25, .50$, and .75 represent the $1^{\text {st }}, 2^{\text {nd }}$, $3^{\text {rd }}$, and $4^{\text {th }}$ quarter of a year. For example, in Table 1 , the date when .10 BAC law took effect in Alaska is 83.00, which means that its effective date is estimated to be in January/February/March of 1983. The .08 BAC, ALR, and Zero Tolerance 21 laws, on the other hand, were passed in the last decade or so, and information such as implementation dates including specific months was available. Thus, the dates used for these three laws include the exact months and years.

To simplify the analysis, the effective dates of all the laws will be converted to decimal numbers with units in years. The estimated dates for .10 BAC and MLDA-21 laws are already in decimal numbers with units in years. The dates for the other laws will have to be converted by changing the month to fraction of a year (i.e., dividing by 12).

\section{Table C-1: Numeric Variables - Representing Months and Years Of the Effective Dates of Alcohol Laws}

\begin{tabular}{|c|c|}
\hline Alcohol Laws & $\begin{array}{c}\text { Variables (Units in } \\
\text { Years) }\end{array}$ \\
\hline .10 BAC & PT10_EFF_DTE \\
\hline MLDA-21 & MLDA21_EFF_DTE \\
\hline .08 BAC & PT08_EFF_DTE \\
\hline Zero Tol-21 & ZT21_EFF_DTE \\
\hline ALR & ALR_EFF_DTE \\
\hline
\end{tabular}

To estimate the effects of the laws, another set of variables (independent variables) are defined - the variable names are listed in Table C-2. As mentioned in the report, since both MLDA-21 and Zero Tolerance laws were mandated to target youths and to prevent them from drinking and driving until they reach the age of 21, only drivers who are younger than 21 years of age are included in the analysis because the laws added no benefits to those age 21 and older. The independent variables MLDA21 and ZT21 are defined as follows:

0 when the driver is 21 years of age or older

0 when the driver is less than 21 years of age and the crash occurred before the laws took effect in the State 
1 when the driver is younger than 21 years of age and the crash occurred after the laws took effect in that State.

For the BAC and ALR laws, drivers of all ages are affected by the laws. For all drivers, the variables PT10, PT08, ALR are set to 0 if the crash occurrence is prior to the effective dates and 1 if it is after.

Table C-2: Regression Variables for the Effects of Alcohol Laws

\begin{tabular}{|c|c|c|}
\hline Alcohol laws & $\begin{array}{c}\text { Variables for the } \\
\text { immediate effects }\end{array}$ & Drivers' age \\
\hline .10 BAC & PT10 & All \\
\hline MLDA-21 & MLDA21 * & Less than 21 \\
\hline .08 BAC & PT08 & All \\
\hline Zero Tol-21 & ZT21 * & Less than 21 \\
\hline ALR & ALR & All \\
\hline
\end{tabular}

* denotes that this variable is set to zero for all drivers age 21 and older 


\section{Appendix E}

This section of code creates a dataset MI_ALLVAR, which is a result of a merge between the crash data file that includes all control factors already discussed in the previous sections and the multiple imputation dataset - with crash information at the person level from calendar years 1982-2005. As previously discussed, under the multiple imputation - each missing BAC value is replaced by 10 imputed values. Hence, in each multiple imputation data file in FARS, there are ten imputed values P1 - P10 for each driver in FARS. In the cases where BAC was actually measured, the values of P1 - P10 are identical and equal to the measured BAC. But if BAC was not measured, P1 - P10 may have up to 10 different values, ranging from zero upwards. These imputed values (P1P10) are scaled values of BAC by a factor of 100 (i.e., 10 actually corresponds to a BAC value of .10).

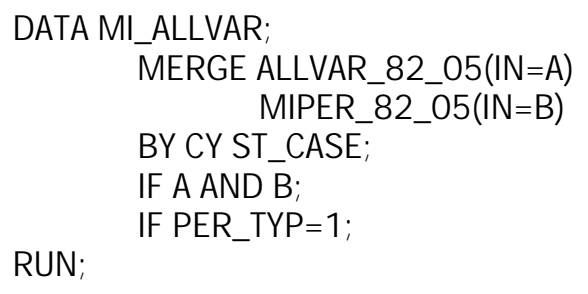

The macro MI in the first step of the next segment runs through each of the 10 imputations and assigns values of BAC to whatever the value of the imputation. In other words, this dataset generates ten [ $\mathrm{N} \mathrm{x} 1]$ matrices of imputed $\mathrm{BAC}$ values, where $\mathrm{N}$ is the number of FARS cases of drivers involved in fatal crashes during 1982-2005. The second dataset sorts these matrices by order of imputation and assigns values to the dependent variable DRV_BAC to 0 or 1 (dataset BAC) depending upon the value of the imputation. In other words, if the value of the imputation is equaled or greater than 8 (BAC .08 or above) then DRV_BAC equals 1 , otherwise it equals 0 .

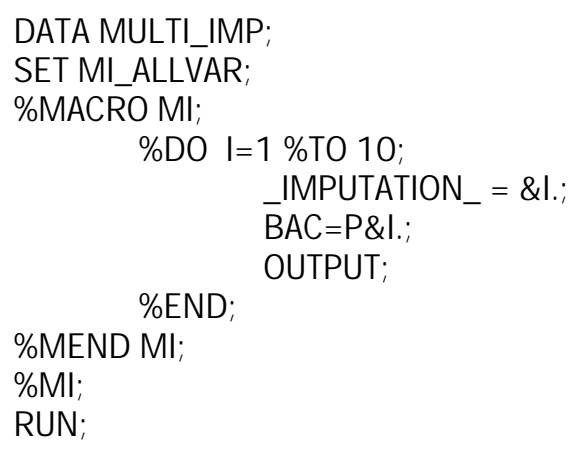


RUN;

DATABAC;

SET MULTIIMP;

IF $B A C<8$ THEN DRV_BAC $=0$;

IF BAC $>=8$ THEN DRV_BAC $=1$;

RUN;

The first statement of the next segment creates datasets containing parameter estimates and corresponding covariance matrices computed by a logistic regression analysis (PROC LOGIST) for each of the ten imputed datasets (matrices). These estimates are then combined using PROC MIANALYZE to produce valid statistical inferences about the model parameters.

PROC LOGIST DATA=BAC;

* CLASS DRVMALE WEEKDAY NITE RURAL SPDLM55 PT10 MLDA21 ALR PT08 ZT21;

MODEL DRV_BAC(EVENT $\left.=^{\prime} 1^{\prime}\right)$ =DRVMALE DRV_AGE WEEKDAY NITE SPDLIM55 PTI0 MLDA21 ALR

PT08 ZT21/C̄OVB;

BY IMPUTATION ;

ODS̄ OUTPUT PARAMETERESTIMATES=LGSPARMS

RUN;

COVB=LGSCOVG;

PROC MIANALYZE PARMS=LGSPARMS

COVB(EFFECTVAR $=$ STACKING) $=$ LGSCOVB;

MODELEFFECS INTERCEPT DRVMALE DRV_AGE WEEKDAY NITE SPDLIM55 RURAL

RUN;

AD)_BEER_COÑS PTT10 MLDA21 ALR PT08 ZT21; 

DOT HS 810942

May 2008

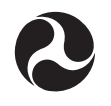

U.S. Department of Transportation

National Highway

Traffic Safety

Administration

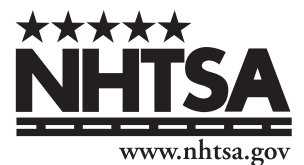

